\title{
Field Measurements of Tracer Gas Transport by Barometric Pumping
}

\author{
Prepared by: \\ S-Cubed, A Division of Maxwell Laboratories Inc. \\ P.O. Box 1620, La Jolla, CA 92038-1620 \\ Peter L. Lagus \\ Lagus Applied Technology \\ 11760 Sorrento Valley Rd, San Diego CA 92121 \\ William B. McKinnis \\ Lawrence Livermore National Laboratory \\ P.O. Box 45, Mercury NV 89023
}

RECEVIV D

Joseph R. Hearst, Norman R. Burkhard and Charles F. Smith

Lawrence Livermore National Laboratory

P.O. Box 808, L-221, Livermore CA 94550

July 28, 1994

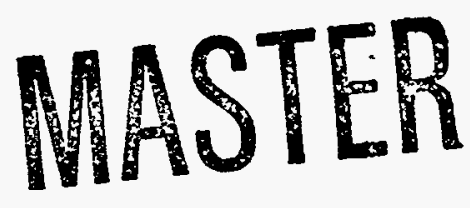

: 


\section{DISCLAIMER}

Work performed under the auspices of the U.S. Department of Energy by Lawrence Livermore National Laboratory under contract number W-7405-ENG-48.

This document was prepared as an account of work sponsored by an agency of the United States Government. Neither the United States Government nor the University of California nor any of their employees, makes any warranty, express or implied, or assumes any legal liability or responsibility for the accuracy, completeness, or usefulness of any information, apparatus, product, or process disclosed, or represents that its use would not infringe privately owned rights. Reference herein to any specific commercial products, process, or service by trade name, trademark, manufacturer, or otherwise, does not necessarily constitute or imply its endorsement, recommendation, or favoring by the United States Government or the University of California. The views and opinions of authors expressed herein do not necessarily state or reflect those of the United States Government or the University of California, and shall not be used for advertising or product endorsement purposes. 


\section{TABLE OF CONTENTS}

\section{Page}

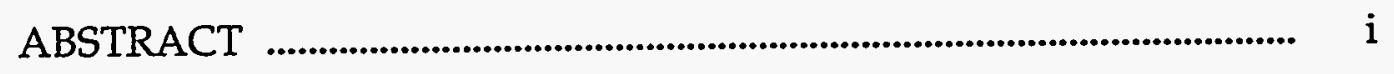

INTRODUCTION ..................................................................................... 1

KAPELLI SITE DESCRIPTION ........................................................... 3

INJECTION EXPERIMENT AT KAPELLI ................................................ 5

PASSIVE TRANSPORT BY BAROMETRIC PUMPING ...................... 7

RADIOACTIVE TRACERS ........................................................................ 10

COMPARISON WITH NUMERICAL SIMULATIONS ........................ 12

THE EXPERIMENT AT TIERRA ............................................................ 17

SUMMARY AND CONCLUSIONS .......................................................... 20

ACKNOWLEDGEMENTS ........................................................................ 23

REFERENCES ....................................................................................... 23

FIGURES …..................................................................................... 25

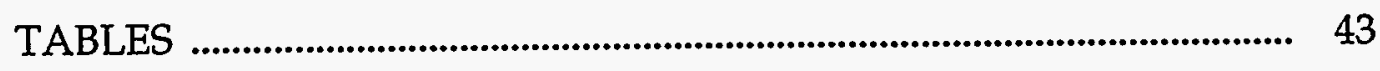


Vertical gas motions induced by barometric pressure variations can carry radioactive gases out of the rubblized region produced by an underground nuclear explosion, through the overburden rock, into the atmosphere. To better quantify the transit time and amount of transport, field experiments were conducted at two sites on Pahute Mesa, Kapelli and Tierra, where radioactive gases had been earlier detected in surface cracks. At each site, two tracer gases were injected into the rubblized chimney $300-400 \mathrm{~m}$ beneath the surface and their arrival was monitored by concentration measurements in gas samples extracted from shallow collection holes. The first "active" tracer was driven by a large quantity of injected air; the second "passive" tracer was introduced with minimal gas drive to observe the natural transport by barometric pumping. Kapelli was injected in the fall of 1990, followed by Tierra in the fall of 1991. Data was collected at both sites through the summer of 1993.

At both Kapelli and Tierra, no surface arrival of tracer was observed during the active phase of the experiment despite the injection of several million cubic feet of air, suggesting that cavity pressurization is likely to induce horizontal transport along high permeability layers, rather than vertical transport to the surface. In contrast, the vertical pressure gradients associated with barometric pumping brought both tracers, active and passive, to the surface in comparable concentrations within three months at Kapelli, whereas 15 months elapsed before surface arrival at Tierra. At Kapelli, a quasisteady pumping regime was established, with tracer concentrations in effluent gases 1000 times smaller than concentrations thought to exist in the chimney. Tracer concentrations observed at Tierra were ty pically an order of magnitude smaller. Comparisons of these observations with theoretical calculations suggest that the gases are traveling through $\sim 1$ millimeter vertical fractures spaced 2-4 meters apart. This interpretation is consistent with borehole observations and with the prevalence of tracers in randomly collected soil gas samples. 


\section{INTRODUCTION}

Since 1983, radioactive gas seepage has been detected on five of the underground nuclear tests conducted on Pahute Mesa at the Nevada Test Site [1]. Tierra was among the earliest and largest in release; Barnwell was the most recent. In all cases, the seepage has been attributed to the so-called "atmospheric pumping" or "breathing" process which is driven by cyclical changes in barometric pressure. Although the associated levels of radioactivity have never posed a health hazard, the Containment Program at Lawrence Livermore National Laboratory has made an effort to better understand this process which causes a gradual release of contaminated gases over periods of weeks, months, and even years after an explosion. Beyond its application to underground nuclear testing, this knowledge is currently being used to estimate gas transport from underground waste repositories sited above the water table.

An underground explosion produces a large spherical cavity which usually collapses within hours to days. On the part of Pahute Mesa where . postshot breathing is most prominent, the combination of the burial depth and the geometry of the rock layering commonly allows the collapse to reach only part of the way to the earth's surface, as illustrated schematically in Figure 1. The collapsed region, called a chimney, is highly recompacted at its base but becomes looser near the top. Accordingly, the upper chimney is likely to contain most of the void volume and radioactive gases produced by the explosion. Thus, if the rock above the chimney should contain vertical fractures, as it sometimes does on Pahute Mesa, there is some possibility that the chimney gas might leak to surface. Fortunately, most of the gas pressure associated with the explosion is dissipated by cooling and steam condensation before and during collapse, so leakage does not normally occur soon after the explosion. Instead, it is usually observed a month or two later when the barometric pressure is falling sharply.

A conceptual model of the barometric pumping process is shown schematically in Figure 2. As the barometer falls, chimney gases are drawn upward through fractures. Conversely, a rising barometer pushes fresh air 
downward. Thus, the interface between fresh and contaminated gases moves cyclically up and down. At the same time, contaminated gases are diffusing horizontally from the fractures into their porous walls. Thus, some of the contaminated gas carried high on an upstroke will remain in the fracture wall during the next downstroke, allowing it to be carried even higher during the next upstroke. This ratchet-like mechanism is capable of carrying gases to the surface during a month or two of stormy weather. Within a year or two, the pumping process reaches a quasisteady state in which the outward flow of contaminated gas is nearly the same for each successive cycle, remaining so for many years thereafter. However, prior to the present work, there has been very little field data which could be used to verify this conceptual model and its mathematical expressions.

The purpose of the present field experiments was to obtain data concerning transit time, dilution, areal distribution, and total amount of contaminant transport by barometric pumping. The primary goals were improved understanding and model verification as well as improved characterization of fractured rock masses. We were particularly anxious to learn whether breathing cracks are a curious anomaly or, alternatively, a widespread phenomenon. Also, we wondered whether site specific features of particular nuclear tests have played a significant role in their seepage to the atmosphere. The results reported here have shed considerable light on all these questions, as well as some other questions we had not previously thought to ask.

The present paper will begin with a complete discussion of the experimental observations made at the Kapelli site over a 1020 day period from 1990 to 1993. Interpretation of that data, together with related calculations and conclusions, will then be presented before finally turning to a discussion of the Tierra experiment. The closing section includes a summary of all of the observations. 


\section{KAPELLI SITE DESCRIPTION}

Kapelli is situated about midway between the East and West Greeley Faults; the latter of which is indicated on the left side of Figure 1. The burial depth of the explosion was 640 meters and the top of the rubblized chimney is believed to be 320 meters below the surface. Between the chimney top and the surface there are two geologic layers of nearly equal thickness. The upper layer is the Timber Mountain tuff which is the surface member at nearly all of the Pahute Mesa sites where radioactive gas seepage has occurred as a result of barometric pumping [1]. The layer beneath is a vitric bedded tuff. Borehole movies of the Kapelli emplacement hole show vertical fractures running some $60 \%$ of the hole length in the upper layer and $15 \%$ in the lower layer, suggesting that the average spacing between vertical fractures is on the order of 2 to 7 times greater than the 2.5 meter diameter of the emplacement hole.

Measurements of pressure in the capped postshot hole (shown in Figure 1) indicate that the Kapelli chimney breathes very freely through the fractured overburden. As seen in Figure 3, the subsurface pressure follows the barometric pressure with less than $50 \%$ attenuation and only moderate time lag. Comparison of these measurements with model calculations suggests that the bulk permeability of the overburden is on the order of 50-150 Darcies, depending on the assumptions made in unfolding the data. A value of 50 Darcies corresponds to the conceptual model of Figure 2, with a well connected rubble zone containing one cavity volume of gas located 320 meters below the surface. The larger value of 150 Darcies was inferred from a model [2] which treats the overburden and the rubblized chimney region as a single homogeneous layer having an air-filled porosity of $10 \%$ and a depth of 500 meters. Whatever the details of the unfolding model, the inferred large-scale permeability is a few orders of magnitude greater than the milliDarcy permeability of the rock matrix, indicating that essentially all of the vertical gas flow travels through fractures.

A prominent surface crack, which was disturbed by the Kapelli event, was found to exhale radioactive gases during barometric lows occurring a few months after the event. The crack is located near the circular exclusion fence 
about 220 meters from surface ground zero, as illustrated in the upper left corner of Figure 4. The surface expression of the crack, which was quite obvious immediately after the explosion, has been gradually filled with alluvium so that it is now barely visible to an untrained eye, although still easily identified by an experienced geologist.

To monitor the arrival of tracer gases, an array of surface tarps and shallow holes were emplaced along the crack as indicated schematically in the central portion of Figure 4. The two tarps labeled T1 and T2 are rectangular sheets of transparent plastic 2 to 3 meters on a side, held down at their edges by cobble-size rocks and dirt. The five nearby holes were each drilled to a depth of 3 meters and cased with a $3 "(7.6 \mathrm{~cm}$ diameter) PVC pipe having perforations over its lower half. The surface gap between the hole and the PVC pipe was sealed by tamping with an annular ring of twisted plastic sheeting and covering with dirt. The top of each PVC casing was fitted with a plastic cap having pass-through holes for a pair of $1 / 4^{\prime \prime}(0.63 \mathrm{~cm}$ diameter) plastic tubes which could be connected to an air pump to circulate the gasses in the hole. Gas samples were extracted from this circulation loop by inserting a hypodermic syringe into a rubber septum located on the outlet side of the pump. The tarps were sampled by piercing a hypodermic syringe through the plastic tarp. Each sample was drawn with a new syringe. During the first year of the experiment, the syringe samples were analysed at the test site within an hour or two after after extraction. In later years, the air pump was. used to fill Tedlar sample bags which were then shipped from NTS to San Diego for analysis. Several tests were performed to ensure that both procedures yielded the same results.

Tracer gas concentrations were measured by injecting syringe samples into an electron-capture gas chromatograph which utilizes the high electron affinity of gases with halogen group elements to provide a measurable signal. The chromatographs we used are designed and built by one of us (PLL) and are optimized for the detection of the particular tracer gases we used, SF6 and halocarbon 13B1, which have detection thresholds of 3-5 ppt and 50-100 ppt (parts per trillion), respectively. A measurement accuracy of $10-20 \%$ can be achieved over a very broad range of concentration by carefully diluting samples which are more than 2-3 orders of magnitude above the threshold. To 
ensure accuracy, periodic recalibrations are made by injecting syringe samples having known concentrations of tracer gases. The results of these measurements are reported in Tables 1 through 3.

\section{INJECTION EXPERIMENT AT KAPELLI}

During the active phase of the Kapelli experiment compressed air was blown into the chimney through the postshot hole shown previously in Figure 1. The first attempt at injection was unsuccessful because the hole was plugged near the bottom of the casing at a depth of 500 meters. We had some prior warning that the hole might be plugged because recent measurements of pressure in the capped hole had hardly responded to changes in barometric pressure (in contrast to the strong response of the earlier measurements in Figure 3) and we also had difficulty in extracting gas samples from the pipe prior to attempting injection. However, after opening the hole with a high pressure water pump, air could be injected at a rate of $0.7 \mathrm{~m} 3 / \mathrm{s}$ (1500 SCFM) with a driving pressure of 10 bars ( $150 \mathrm{psig}$ ), in agreement with design calculations of the frictional pressure drop along the pipe.

The active tracer gas, halocarbon $13 \mathrm{~B} 1$, was introduced into the hole through a fitting in the injection manifold. The total amount injected was $45 \mathrm{~kg}$ which expands to a volume of $7 \mathrm{~m}^{3}\left(250 \mathrm{ft}^{3}\right)$ at the nearly standard conditions of temperature and pressure existing within the chimney. Throughout the subsequent injection of air, the pressure regulator on the compressor maintained a relatively constant driving pressure around 10 bars (130-150 psig), corresponding to a flow rate of about $0.7 \mathrm{~m}^{3} / \mathrm{s}$ (1300-1500 SCFM). The instantaneous and cumulative flow rate were continuously measured and periodically recorded.

The gradual increase in the chimney pressure was monitored by periodically closing the valve between the compressor and the hole for five minutes and measuring the "shut-in" pressure at the top of the hole." As seen in Figure 5, the pressure increased by 40 millibars within the first two days of injection, at which time we were asked to suspend operation for about 20 hours during the conduct of an underground nuclear test. Within two hours after shutting in, the chimney pressure had fallen to about half of the 40 millibars 
which had been earlier measured at the end of a five minute shut-in period. During the 20-hour exclusion period, the pressure fell about $30 \%$ more to 13 millibars. Thereafter, an additional five days of injection raised the chimney pressure to a nearly steady level of 55 millibars, as measured in our standard five minute shut-in. However, in rough agreement with our earlier experience, the long term shut-in at the end of injection indicated that the equilibrated chimney pressure was about two-thirds that great at 33 millibars. The noise in the pressure measurements is largely due to the fact that the transducer resolution is only a few millibars (ie. $0.1 \mathrm{psi}$ ). Each of the reported data points is actually the difference between the manifold pressure and the external barometric pressure. As the barometer experienced only a moderate 8-millibar cycle during the injection (dotted line in Figure 5), we did not make any adjustments to the raw data nor did we include this affect in the comparative calculations discussed below.

The two comparative calculations (solid lines) in Figure 5 were executed with a numerical model [3] which assumes vertical flow through a fractured permeable medium like that depicted earlier in Figure 2. In both calculations gas is injected at a constant rate into a rubblized region having a wellconnected volume equal to that of the cavity produced by the explosion. In both, the bulk permeability of the 320 meter overburden is taken as 50 Darcies to conform with the values used in the previous comparisons between surface and chimney pressures driven by the barometer. The upper calculation of Figure 5 corresponds to the actual injection rate, $Q$, while the lower calculation labeled $Q / 2$ has half that flow rate. Since these two calculations bracket the data, it appears that somewhere between all and half of the injected flow travelled vertically, as assumed in the model. In any case, there appears to be a reasonably close correspondence between the measured data and these very simple calculations which use apriori estimates of overburden permeability and subsurface void volume.

Despite the injection of $427,000 \mathrm{~m}^{3}\left(15,000,000 \mathrm{ft}^{3}\right)$ of air, we observed no tracer arrival during the active phase of the experiment. This is somewhat surprising, as the volume of gas injected is roughly one half of the cavity volume produced by the explosion and is nearly equal to the total gas-filled porosity of a 320-meter overburden column having a radius equal to that of the 
cavity produced by the explosion ( $\sim 60$ meters). The slow arrival of the active tracer is, therefore, suggestive that a substantial fraction of the injected gas may have moved horizontally rather than vertically, in keeping with the earlier interpretation of the pressure buildup data. In any case, the absence of tracer in our collection holes and tarps was our first clue that "the" Kapelli crack was not such a highly preferred pathway as we had once imagined. Moreover, we could find no hint of the tracer in air samples and soil gas samples which were collected in broader walking surveys taken on a few occasions during the injection period. The only detectable evidence of the tracer was in samples which were drawn directly from the interface between the injection pipe and the surrounding cement, some 200 meters away from the surface crack. Even this was a relatively subtle seepage, which diminished over the course of injection.

Near the end of the active injection period, the second "passive" tracer gas was injected in a single slug, just as the first had been. The volume of the passive SF6 tracer was nearly identical to that of the active 13B1, under conditions of standard pressure and temperature. Thus, the primary difference between the two is that the passive tracer was driven by only two hours of compressor operation or, equivalently, only $2 \%$ of the total volume of air injected. After recapping the hole on October 2 of 1990, we returned home to await the arrival of winter storms and the associated cycles of barometric pumping which we hoped to observe.

\section{PASSIVE TRANSPORT BYBAROMETRIC PUMPING}

The barometric pressure history following the injection period is shown. in Figure 6. This data was measured in Area 20 of the Nevada Test Site by the Weather Service Nuclear Support Office of the National Oceanographic and Atmospheric Administration. We had planned to return to Kapelli when the first severe storm was imminent. Unfortunately, the first two storms coincided with Thanksgiving and Christmas, making it difficult to muster the required personnel on short notice. So it wasn't until early January that we returned to the site. 
Both tracer gases, active and passive, had reached the surface during our three month absence. The bar graph of Figure 7 depicts the concentrations measured in a typical set of samples gathered at 13:00 on January 23, 1991 when the barometer was falling and the chimney was exhaling gases through fractures. The nearly equal concentrations of active and passive tracers suggests that barometric pumping was the primary process causing transport of both gases from the chimney to the surface. The two tarps , T1 and T2, differed in concentration by nearly two orders of magnitude, a disparity which persisted in every set of samples. In contrast, the collection holes were much more uniform than expected, differing by less than one order of magnitude within any given set of samples. There were, of course, considerable differences among sets of samples collected at different times, because of long term trends as well as the cyclical variations associated with each barometric cycle of inhalation and exhalation.

During a period of increasing barometric pressure, the chimney is inhaling fresh air rather than exhaling contaminated gas. The data set of Figure 8 was gathered during such a period of inhalation, just 20 hours after the exhalation data of Figure 7. Since the tarps are devoid of tracer, it appears that during a rising barometer contaminated gases under the tarps are pushed back down into the earth and are soon replaced by inward seepage of fresh air from the borders of the tarps. In contrast, the capped collection holes retain a longer memory of the tracers, because the holes have contact with the less mobile gases residing within the porous rock matrix.

Soil gas samples were also collected on a few occasions to see if the tracer gases might be breathing out of the ground in places other than "the" Kapelli crack which was the focus of our attention. Figure 9 shows a complete set of samples taken at 16:00 on 2/28/91 when the barometer had fallen by about 20 millibars over the preceding two days. The F-series of samples shown on the right side of Figure 9 were gathered by simply plunging syringes into the soil at regular intervals along the perimeter exclusion fence. These samples were analysed only for their passive SF6 tracer content, since it has a lower detection limit than the active 13B1. Roughly $30 \%$ of the F-samples contained only a few parts per trillion of SF6, which corresponds to the background concentration existing prior to our experiments. However, it is seen that the 
highest $25 \%$ have concentrations greater than tarp\#2, suggesting that these locations may be located near breathing cracks which have similar transport characteristics but less obvious surface expression than "the" Kapelli crack. Indeed, it is easy to imagine that a shallow layer of surface alluvium above a crack could disperse the rising gas stream, causing a ten to hundredfold dilution of the surface effluent, as appears to be the case in comparing tarp\#1 with either tarp\#2 or the free field $\mathrm{F}$-samples.

To further explore the areal distribution of tracer gases, four additional sampling holes were drilled during the summer of 1992 . All were located just outside the perimeter exclusion fence at a radial distance of $\sim 220 \mathrm{~m}$ from surface ground zero, as were all of the original holes and tarps. Holes \#6 and \#7 were located $\sim 15^{\circ}$ and $\sim 30^{\circ}$, respectively, in the counterclockwise direction from the original array of holes, and they were situated in the general vicinity which had produced soil gas samples (F-samples in Figure 9) having the highest tracer concentration. Holes \#8 and \#9 were almost diametrically opposed to \#6 and \#7, and they were sited in the area which had produced the least concentrated soil gas samples.

The comparison of gas sample data in Figure 10 shows that concentrations in holes \#6 and \#7 are greater than those observed in tarp\#1 and hole\# 1 which were the two most productive measurement locations in the original array. This situation persisted in all such comparisons. It is also observed that the concentration in hole \#8 clearly indicates the presence of tracer, even though it was sited in a location which had been counter-indicated by earlier soil gas samples, supporting the hypothesis of a fairly broad areal distribution of tracer. Finally, in contrast to all other locations, holes \#6 and \#7 consistently exhibit active tracer concentrations greater than passive tracer concentrations, suggesting that the injected gas may have pushed the active tracer horizontally toward these holes. However, we do not believe that the active tracer was driven vertically to the surface by the injected gas since we found no tracer in soil gas samples collected from this general vicinity during the injection period.

Figure 11 presents a time history of passive SF6 concentrations measured at Kapelli. The square symbols indicate measurements in tarp\#1, 
the circles represent the average of samples taken from the original five holes, and the triangles show the concentration in the more remote hole \#7. Much of the scatter in the data is due to the timing of sample collection relative to rises and falls of the barometic pressure. In keeping with the earlier discussion of bar graps in Figures 7 and 8 , the tarp concentrations (squares) should be above the hole concentrations (circles) when gases are breathing out of the ground and vice versa. If we momentarily disregard the data sets (open symbols in Figure 11) in which the barometer was rising, it is seen that the data from holes \#1 through \#5 is relatively flat in time, whereas concentrations in hole \#6 trend upward, while the tarp data decreases by nearly a decade. The downward trend of the tarp data may be partly attributed to the fact that the first year of samples were collected on dedicated trips which allowed us to select optimal sampling times during a one or two day stay at the Kapelli site, whereas sampling in the later years was done in less flexible half-day trips. Subsurface mixing and dilution could also explain the downward trend of the tarp data, as explained further below.

\section{RADIOACTIVE TRACERS}

The radioactive Krypton-85 produced by the 1984 Kapelli explosion serves as another tracer gas. Figure 12 shows Krypton concentrations in samples collected from the Kapelli crack at four different times (all radioactively decayed to the same point in time), together with the passive SF6 concentrations which were detected on the last two of these occasions and at two later times. Each data set represent the highest concentrations observed at any time during the each of the noted years, except for the second set which reports the highest concentrations observed during the injection period.

$\therefore$ To provide a meaningful comparison, these surface concentrations are reported in a relative sense by dividing the measured surface concentration of each gas by its subsurface concentration thought to exist in the chimney. Now, the Krypton is believed to be very well mixed with the air in the chimney, both by the explosion itself and by the passage of time. Moreover, the subsurface concentration of Krypton was measured in 1985 samples of chimney gas which were radioactively decayed, by half-life mathematics, to 
predict the current chimney concentration. Conversely, the SF6 is not so well mixed and its subsurface concentration can only be roughly estimated by forming the quotient of the volume of tracer injected and the estimated free volume of the chimney. As this estimate tacitly assumes the SF6 to be well mixed, it should tend to underestimate its subsurface concentration (in some regions, at least) and, hence, overestimate the relative concentrations, particularly at early times when there has been little time for subsurface mixing. This, we believe, is the reason why the SF6 appears to be nearly an order of magnitude more concentrated than the Krypton in the barometric lows of $2 / 91$ and $3 / 91$.

The SF6 data shown in Figure 12 for 1992 and 1993 further support the hypothesis that the very high SF6 concentrations observed in 1991 are indicative of very high subsurface concentration during the first year after injection. Indeed, it is seen that the 1992 and 1993 measurements for SF6 are quite comparable to the very stable levels of Krypton observed from 19851991. This would suggest that both tracers, Krypton and SF6, are being transported by the same physical process and that the rate of depletion is very small, in keeping with the numerical calculations presented later.

The most important quantitative observation to be drawn from Figure 12 is that both of the tracers, Krypton and SF6, have experienced a very substantial dilution, typically around $10^{-3}$, during their travel through $330 \mathrm{~m}$ of fractured rock. This can be said even though these samples include the highest concentrations which were ever observed in gas samples from the Kapelli crack. Such a large dilution has important implications regarding the severity of the associated health hazard, and it also provides information regarding the areal distribution of cracks, as further discussed in upcoming comparisons with numerical simulations.

It is also seen in Figure 12 that the Krypton concentration in tarp\#1 was remarkably small during the injection experiment which ran from 9/2410/2 of 1990. The two samples collected on $9 / 26$ and 10/1 had a nearly identical concentration which was an order of magnitude smaller than the concentrations observed during barometric pumping. Another sample (not 
shown), extracted from hole\# 5 , had a concentration about $1 / 3$ as large as tarp\#1, in keeping with subsequent suites of data.

It is somewhat surprising to find such small concentrations during injection, considering that the measured chimney overpressure was on the order of 33-55 millibars for a number of days, which would appear to be a more severe condition than any of the weather cycles we have ever observed, probably more severe than several of them combined. Moreover, the barometric pressure was falling slightly during most of the injection period which should have aided the upward transport, rather than opposing it. Finally, and most importantly, the Krypton was already present in the porous walls of the fracture, so its low concentration in the effluent was not a . consequence of transit time (as it was for the active 13B1 tracer which didn't arrive during injection) but rather an indication that the vertical gas velocity induced by our compressor was considerably smaller than that induced by a comparable (ie., 33-millibar) reduction in barometric pressure. Thus, the low concentration of Krypton during injection lends very strong support for our earlier conjecture that a substantial fraction of the injected gas must have gone horizontally rather than vertically.

\section{COMPARISON WITH NUMERICAL SIMULATIONS}

To aid in the interpretation of tracer concentration data, computer simulations were executed using a numerical model [3] of the barometric pumping process shown schematically in Figure 2. The model is intended to be as simple as possible while still incorporating all of the important physical mechanisms and all of the available data concerning material properties. In the absence of detailed knowledge concerning the number of cracks and their individual characteristics, the model treats a family of identical vertical fractures, spaced uniformly apart by intervening rock slabs having a gas-filled porosity of $10 \%$ and an effective gas permeability of 1 milliDarcy, consistent with core sample measurements. The bulk gas flow moves vertically along fractures and horizontally within the permeable matrix. Tracer gases are transported by advection and by molecular diffusion, the later being particularly important in the horizontal exchange of tracer between mobile gases within the cracks and the relatively stagnant gases within the adjacent 
permeable matrix. The molecular diffusivity is on the order of $3 \cdot 10^{-6} \mathrm{~m}^{2} / \mathrm{s}$ $[4,5]$ for the 13B1 and SF6 which have nearly identical molecular weights of 148 and 146, respectively. The $30 \%$ greater diffusivity of the lighter Krypton85 has only a negligible influence on calculated transport.

Attention is focused on vertical fractures because our primary interest is in vertical transport driven by the vertical pressure gradients resulting from changes in barometric pressure. No attempt will be made to calculate the three-dimensional gas flow which apparently occurred during the active injection experiment, as this would be sensitive to the unknown horizontal permeabilities of the different geologic layers. Also, the similarity of outcome for all three tracers (13B1, SF6, and $\mathrm{Kr}-85$ ) indicates that the emplacement process (active, passive, or explosive) is not a critical consideration in the ensuing vertical transport. Thus, the analysis is limited to the more tractable problem of predicting the vertical transport induced by barometric pumping.

In keeping with earlier calculations of subsurface pressure response, the depth of the fractured overburden is taken as 320 meters and the gas volume of the upper chimney void is assumed equal to that of the explosively produced cavity. As before, the upper chimney is supposed to be well enough connected that it breathes as a single unit having a relatively uniform pressure at any given instant in time. Similarly, the upper chimney is assumed to be well enough mixed that the tracer concentration is relatively uniform therein, with the initial concentration taken as $7 \mathrm{ppm}$ based on the estimated chimney volume and the injected tracer volume noted earlier. After explaining the results for this well mixed "cavity" model, some comparative results will be presented for an alternative "layered" model.

The only unknown or "adjustable" parameter in these calculational models is the spacing between the identical vertical fractures in overburden layer of Figure 2. For any chosen fracture spacing, the corresponding fracture aperture is then calculated as that particular value which produces a bulk overburden permeability of 55 Darcies, thereby ensuring that the subsurface pressure response will be in agreement with the measurements shown previously in Figure 3. For fracture spacings from 1 to 8 meters, the crack aperture ranges from about 1 to 2 millimeters. 
The measured barometric pressure history of Figure 6 is used as input data for the numerical simulations of barometric pumping. Also, since all fractures are identical, each simulation need only address one typical fracture and its immediate surroundings, with proper attention given to the enforcement of symmetry considerations. The computational domain is covered with a rectangular grid having 100 divisions along the crack and 20 divisions into the permeable wall, with variable spacing used to optimize the coverage. This level of resolution has proved adequate in a number of closely related test problems [3]. The computational time step is limited by the Courant stability restriction of the flux corrected transport scheme used to advect the tracer [3]; 600,000 time steps are typically required for the 3-year simulations presented here.

Figure 13 shows the calculated concentration of tracer gas at the surface for a fracture spacing of 4 meters. The concentration is expressed as a fraction of that existing within the chimney (ie. a relative concentration) as in the previous Figure 12. The line which looks like a sequence of vertical spikes indicates the tracer concentration in the crack at the surface. This concentration varies erratically, depending upon the direction of the gas flow. During inhalation of fresh air, the tracer concentration near the surface is nearly zero, whereas exhalation promptly draws contaminated gas from below, in a manner quite similar to the erratic behavior of tracer concentrations measured within the tarps or the free-field soil gas samples collected from the surface. In contrast, the heavy solid line in Figure 13 indicates the tracer concentration within the permeable rock midway between fractures, 6 meters below the surface. This location is sufficiently far from the fracture that the local concentration is controlled mainly by molecular diffusion and, hence, represents a time average of the concentration in the crack. Also, one might imagine that the calculated concentration within the permeable matrix may be somewhat analogous to the concentration measured in the collection holes which were drilled along the crack-line at Kapelli. Moreover, the concentration within the wall provides a well damped "envelope" which can be compared with the tracer measurements made in tents and holes. 
Figure 14 compares the time history of tracer measurements with a series of 3 calculations having different choices of the fracture spacing. The symbols have the same meaning as they did when the same data was displayed on the unscaled vertical axis of Figure 11. The solid lines represent calculated near-surface concentrations in the stagnant gas midway between fractures, as explained just above The measured dilution is typically on the order of $10^{-4}$ to $10^{-3}$, with the most noticeable exceptions occurring when the squares lie below the circles, indicating a period of inhalation rather than exhalation. Most of the other data points are probably indicative of the upper envelope, since our aim was generally to collect samples when the barometer ẉas falling.

In comparing the calculations and data it should be remembered that the earliest data may be high by an order of magnitude because the tracer was not yet well mixed with the cavity gas, as assumed in the modeling. With this in mind, the data and calculations. both suggest a fairly sharp arrival followed by a gradual rise onto a broad plateau which we expect to persist for years.

This comparison of data with calculations further suggests that the crack spacing at Kapelli is on the order of 2-4 meters. Of course, we don't really imagine that identical cracks having such regular spacing might actually exist in nature, but rather that there may be a relatively large number of dissimilar cracks which collectively account for the breathing of the chimney. Indeed, if all of Kapelli's respiration were channeled through a single crack, the concentration of the effluent would be orders of magnitude greater than measured. Conversely, a great many cracks having a spacing of a meter or less would reduce the concentration to $10^{-5}$ which is comparable to the concentration observed in tarp\#2 and in many of the free-field samples of soil gas. In general, a larger number of cracks provides greater surface area for diffusive interaction between the respiration channels and the air-filled porosity of the wall rock, increasing the buffering effect of the overburden. In all likelihood, there are at most a few prominent cracks, like "the" Kapelli crack, with the remainder of the breathing accomplished by a larger number of smaller cracks, after the fashion of the statistical distributions commonly used to describe fractured geologic media. 
The foregoing interpretation of the experiental data is not substantially altered if we adopt a different model of the rubblized region which serves as the reservoir of contaminated gases. Figure 15 illustrates the results obtained by assuming that the tracer gas is initially distributed uniformly throughout a rubblized zone which extends from a depth of 320 meters down to the water table at 700 meters. In contrast to the previous cavity model, the lower region is now treated almost the same as the upper layer except that the porosity is increased to $25 \%$ to account for the subsurface volume produced by the explosion. Also, for simplicity, it is assumed that the fracture spacing in the rubble zone is the same as in the upper layer. This "layered" model predicts a slower arrival and greater dilution that the previous "cavity" model because most of the contaminated gas must now be extracted from the rubble blocks in the lower region by processes of advection and diffusion.

A compelling feature of Figure 15 is that the "layered" model predicts that maximum concentrations will occur for a fracture spacing of $\sim 4$ meters and that this upper bound is similar to the concentrations observed at Kapelli, particularly if we focus attention on the relatively late times at which the layered model should be most relevant. Over time, tracer gases will diffuse into the porous rubble blocks, as presumed in the layered model, while at earlier times the tracer would be concentrated in the more mobile gases which occupy the fracture porosity of the lower region. Thus, we might expect a gradual transition from the behavior predicted by the cavity model to that predicted by the layered model. However, for present purposes it is probably best to emphasize that both models are reasonably consistent with the data and with one another.

Based on the calculations in Figures 14 and 15 it would appear that the first detectable arrival of tracer gas probably occurred about 30-100 days after injection, since a relative concentration of $1 \mathrm{ppm}$ ( $7 \mathrm{ppt}$, absolute) near the bottom of the plot is not much greater than the background concentration of the SF6 existing prior to our experiment. Unfortunately, we did not obtain any measurements early enough to clearly define the first arrival at Kapelli, but we were able to correct this deficiency in the next experiment at Tierra. The transit time is particularly important to the containment of radioactive gases, because it determines the amount of radioactive decay occurring prior 
to the release of gases to the atmosphere. Fortunately, the expected transit time is many times longer than the half-lives of the radioactive Xenons which account for most of the gas radiation associated with underground nuclear explosions.

\section{THE EXPERIMENT AT TIERRA}

The experiment at Tierra is, with very few exceptions, a repetition of the earlier one at Kapelli. Since all of the experimental procedures and interpretive models have already been described, the discussion which follows will be brief. Moreover, by revisiting each of the topics discussed earlier, it will also serve as as review of the principal findings.

Like Kapelli, Tierra is located on Pahute mesa. The burial depth and yield of the two nuclear devices was the same. At both sites the static water level is about 600 meters below the surface. There is no reason to expect that the cavity sizes or the ensuing cavity collapses should differ significantly at the two sites. In both cases the collapse was expected to reach about half way to the surface, leaving roughly 320 meters of overburden rock to contain the radioactive gases.

The geology of the two sites is very similar. The upper 300 meters at Kapelli consists of two layers of nearly equal thickness, a Timber Mountain Tuff (Tmr) which is a partially to densely welded ash-flow tuff lying above a vitric lithic-rich bedded tuff associated with Paintbrush Tuff ( $\mathrm{Tp}(\mathrm{Tb}))$ ). At Tierra, the uppermost 70 meters consists mainly of the moderately welded Ammonia Tanks (Tma) ash flow tuff with the Timber Mountain member (Tmr) extending from that level down to a depth of $400 \mathrm{~m}$.

Borehole camera surveys of the 2.5 meter emplacement holes showed vertical cooling cracks intersecting the hole along $35 \%$ of its length at Kapelli, as compared with $80 \%$ at Tierra. Although we do not expect that all visible fractures will serve as air flow passages, the observation of closer fracture spacing at Tierra, together with our earlier modeling studies, led us to expect a slower arrival of tracer gases at Tierra. This expectation was met. 
Despite the closer fracture spacing at Tierra, the bulk permeability of the overburden appears to be quite comparable to that at Kapelli. This can be seen in comparing the earlier measurements of subsurface pressure response at Kapelli (Figure 3) with those shown in Figure 16 for Tierra. Both figures also show the calculated response for a fractured overburden having a bulk permeability of 55 Darcies. Although the agreement is certainly not precise, both sets of measurements and calculations indicate a subsurface amplitude which is about half that of the barometric pressure measured at the surface. It may be noted, however, that the time lag of the subsurface signal is somewhat greater at Tierra. A number of model parameters were varied in an effort to improve the fit, but none seemed to improve the time lag while still properly predicting the attenuation of barometric pressure cycles and the arrival of tracer gases.

Tierra was injected with tracers and air in the period from August 18-23, 1993, about one year (322 days) after the Kapelli injection. The only significant deviation from the earlier procedure was in switching the roles played by the two tracer gases. SF6 was used as the active tracer because of its lower detection threshold; 13B1 was then introduced as the passive tracer following injection. Although the flow rate and duration of the air injection were essentially the same as before, the subsurface pressure buildup at Tierra was only one tenth of that observed at Kapelli. This, we believe, is indicative of a greater horizontal permeability at Tierra. Considering the layered structure of the geology, it is quite possible that a high permeability layer would significantly increase the horizontal permeability at Tierra, even though the vertical permeability is comparable to that at Kapelli. Horizontal interactions between the subsurface rubble zone and the surrounding rock might also explain the time lag seen in the subsurface response to barometric pressure changes.

Tracer measurements were made using tarps and collection holes the same as those at Kapelli. Tarp\#I was situated on a line of site between the post shot hole and the SGZ about half way between the two. Although this location was intended to be as close as possible to the spot where radioactive gases had been collected in the spring of 1985, there were no surface features to guide the placement. Three holes, \#1 through \#3, were drilled nearby at 
intervals of several meters. The other meassurement stations, including tarp\#2 and holes\#4 through \#6, were streched out along the perimeter at angular locations ranging from $90^{\circ}$ to $150^{\circ}$ counterclockwise from the first cluster. All of the holes and tarps were emplaced roughly 100 meters from the SGZ, about twice as close as they had been at Kapelli.

A time history of the tracer measurements at Tierra is shown in Figure 17. The arrival is much slower than that observed at Kapelli, and the highest concentrations are only $10^{-4}$, as compared with peaks near $10^{-2}$ at Kapelli. However, concentrations were increasing rapidly near the end of the monitoring period and, on the last day of observation $(7 / 7 / 93=1010$ days in Figure $15=688$ days in Figure 17), the tracer concentrations measured at the two sites were nearly the same. This is consistent with the calculational studies, in that differences between curves grow smaller over time, suggesting that a difference in fracture spacing (or another parameter) may cause disparities of arrival time much greater than variations in dilution observed after two or three years of pumping. Indeed, a factor of two difference in the fracture spacing is sufficient to explain the observed differences in arrival times and dilutions at the two sites.

The first year of tracer data from Tierra is difficult to interpret. We suspect that the SF6 concentrations of $\sim 10^{-6}$ ( $\sim 20$ ppt absolute) seen in the first 90 days may be associated with the injection phase of the experiment, since the SF6 was introduced prior to air injection. As a first point in support of this view, there was no hint of the passive 13B1 tracer in the first 90 days. Second, if the SF6 had been brought to the surface by barometric pumping, it should have persisted and probably intensified during the next spring when only background levels ( $<2 \mathrm{ppt}$ ) of SF6 were observed. However, it is possible to counter both points. First, even if the $13 \mathrm{~B} 1$ had been present at $20 \mathrm{ppt}$, like the SF6, it could not have been detected by our instruments; that was the reason for injecting the more easily detected SF6 at the onset. Second, on two of the three spring days which yielded no tracer at Tierra, the levels measured in tarp\#1 at Kapelli were 20 and 83 ppt, far below the 1000 ppt levels seen during a period of falling barometric pressure. Moreover, one might also speculate that the early spike of SF6 seen at Tierra could be caused by the same process, such as incomplete mixing, which caused the early spike of both 
tracers at Kapelli. In view of these uncertainties, it is probably more useful to focus upon the last few data sets which contained significant concentrations of both tracers.

Figure 18 shows the tracer concentrations observed at Tierra on 5/3/93, 600 days after injection. Both tracers are present in comparable concentrations, indicating that they were both brought to the surface by barometric pumping. The uniformity of the samples is remarkable, particularly considering the wide distribution of holes and the fact that the first three holes were intentionally sited in locations believed to be most productive. Both of these observations regarding uniformity were made earlier in discussing Figures 7 and 10 which presented comparable data from Kapelli. The primary difference is that concentrations at Tierra were typically an order of magnitude smaller, except for the last set of measurements on 7/7/93 which disclosed comparable levels of SF6, -1000 ppt, at both sites.

In contrast to Kapelli, the tracer experiment at Tierra yielded relative concentrations at the surface much smaller than those inferred from radioactive gas samples gathered in the spring of 1985 , one month after the detonation of Tierra. At that time the dilution at Tierra was 20:1, as compared with 1000:1 at Kapelli. Although the latter value for Kapelli is quite consistent with our present tracers, the measured dilution at Tierra is now 100 fold greater than in 1985. This lead us to speculate that the radioactive gases traveled to the surface along a pathway, such as an explosively induced fracture or the casing of the post shot hole, which has been sealed over time. Moreover, some of the radioactive gas may have been promptly driven to relatively high elevations by high cavity pressures existing prior to collapse. In any event, those processes and/or pathways are atypical of the barometric pumping process which is currently operative at Kapelli and Tierra..

\section{SUMMARY AND CONCLUSIONS}

The most important feature of the experimental data is the very significant, typically thousand-fold, dilution of the tracer gases during their transport through 300 meters of volcanic rock. A relatively low concentration of contaminants in outflowing gases is of obvious benefit in reducing their rate 
of release to the atmosphere. Moreover, the degree of dilution is not very sensitive to the details of the gas emplacement, as judged by comparison of different tracer gases which were introduced actively, passively, and explosively.

The transit time and dilution of injected tracer gases are, however, strongly dependent upon geologic conditions such as the spacing between fractures. At Kapelli, tracers arrived at the surface in less than three months of barometric pumping, while at Tierra more than 1 year of pumping was required to bring tracers to the surface in concentrations well above background. After two years of pumping, dilutions still differed substantially, even though the two sites are very similar in their subsurface pressure response and measurable rock properties such as porosity, permeability, and water content.

The observed differences in transit times and dilution can, however, be explained by a factor-of-two difference in fracture spacing. Numerical simulations of barometric pumping, suggest that all of the experimental data are consistent with a fracture spacing ranging from 2-4 meters. This estimate of fracture frequency is also reasonably consistent with the borehole observations of vertical cooling cracks and with the observed areal distribution of tracer gases.

Following surface arrival, the barometric pumping process gradually settles into a quasisteady regime in which measured surface concentrations are quite similar for successive weather cycles of comparable severity. We expect this quasisteady pumping process to persist for many years to come, based on model predictions and comparisons of experimental observations spanning nearly ten years. The constancy of the quasi-steady plateau indicates that the subsurface inventory of tracers is being depleted very slowly. This is consistent with the low concentration measured in the effluent gases and with numerically calculated depletion rates of only $\sim 2 \%$ per year.

At both Kapelli and Tierra we were surprised by the uniformity of samples extracted from the several collection holes at any given time. We believe this is party a consequence of horizontal transport by molecular 
diffusion which spreads the contaminated gases deep into the porous fracture walls. Were it not for this, we would expect to observe the enormous disparity of arrival times and concentrations which is normally encountered in tracer transport through fractured rock. It appears that the cyclical nature of the motion, unique to the present application, affords the time required for longrange smoothing of gradients by molecular diffusion. Moreover, the diffusion interaction between flowing gases in cracks and stagnant gases in the porous rock is the primary mechanism which buffers the effluent concentration at a quasisteady level which, we believe, remains stable for years.

Prior to the conduct of these experiments we had not fully appreciated the very important difference-between cavity pressurization, as done in the active injection experiments, and the natural process of barometric pumping. In retrospect, we realize that the localized pressure increase produced by injection may drive gases horizontally as well as vertically, particularly if there happens to be a horizontal layer having a large permeability. In contrast, a lowering of barometric pressure at the surface pulls gases everywhere upward; this pressure differential cannot be relieved by horizontal motion. Because of this, it is easier to suck contaminated gas out of the ground by a reduction in barometric pressure than to blow it out of the ground with the pressure produced by a compressor or, perhaps, an explosion.

Predictions of subsurface transport are plagued by the uncertainties associated with the possible existence of preferential pathways. Even a very ambitious drilling program can never sample a significant fraction of a large rock mass. In contrast, the present experiments have provided an unusual opportunity to observe vertical transport through columns of rock having a diameter of 200 meters of more. Given that the overburden is known to be highly fractured and very permeable, we expected to find highly concentrated gases flowing out of a few prominent fractures. Instead we encountered very dilute gases almost everywhere we looked. The latter situation is clearly favorable to the containment of radioactive wastes whether they are produced by underground nuclear explosions or emplaced within mined repositories. 


\section{AKNOWLEDGEMENTS}

This work was performed under the auspices of the U.S. Department of Energy by Lawrence Livermore National Laboratory under contract No. W-7405-Eng48. The work was supported by the LLNL Nuclear Test Containment Program. The authors are grateful for the approval and encouragement of the Nevada Operations Office of the U.S. DOE and the State of Nevada. We also express our appreciation to the following people who have made essential contributions to the success of the project: Tom Anderson and his postshot crew members; Ted Fanning and his associates from the Radiation Safety staff of Reynolds Electrical \& Engineering Co.; Charlie Steadman and Mark Fair of the Weather Service Nuclear Support Office of NOAA; Bob Dury, Mark Owens, and Ken Raschke of LLNL Nevada; Jeff Brown of Lagus Applied Technology, and Scott Davis of S-Cubed.

\section{REFERENCES}

[1] E. C. Woodward Jr., "Breathing on the Mesa", Proceedings of the Fourth Symposium on Containment of Underground Nuclear Explosions, LLNLCONF-870961, 285-287, 1987.

[2] N. R. Burkhard, J. R Hearst, and J. M. Hanson, "Estimation of the Bulk Diffusivity of Chimneys Using Post-shot Holes", Proceedings of the Fourth Symposium on Underground Nuclear Explosions, LLNL-CONF-870961, 288$351,1987$.

[3] R. Nilson and K. Lie, "Double-Porosity Modelling of Oscillatory Gas Motion and Contaminant Transport in Fractured Permeable Media", International Journal of Numerical and Analytical Methods in Geomechanics, 14, 565-585, 1990.

[4] D. K Kreamer, E. P. Weeks, and G. M. Thompson, "A Field Technique to Measure the Tortuosity and Sorption-Affected Porosity for Gaseous Diffusion 
of Materials in the Unsaturated Zone with Experimental Results from Barnwell, South Carolina”, Water Resources Research, 24 (3), 331-341, 1988.

[5] R. Nilson, E. Peterson, K Lie, N. Burkhard, and J. Hearst, "Atmospheric Pumping: A Mechanism Causing Vertical Transport of Contaminated Gases Through Fractured Permeable Media, Journal of Geophysical Research , in press 1991.

[6] R. Nilson, E. Peterson, K. Lie, N. Burkhard, and J. Hearst, "Barometric Pumping of Contaminated Gases Through Fractured Porous Media", Proceedings of 1991 High-Level Radioactive Waste Management Conference, Las Vegas, Nevada, April 28-May 2, 1991. 


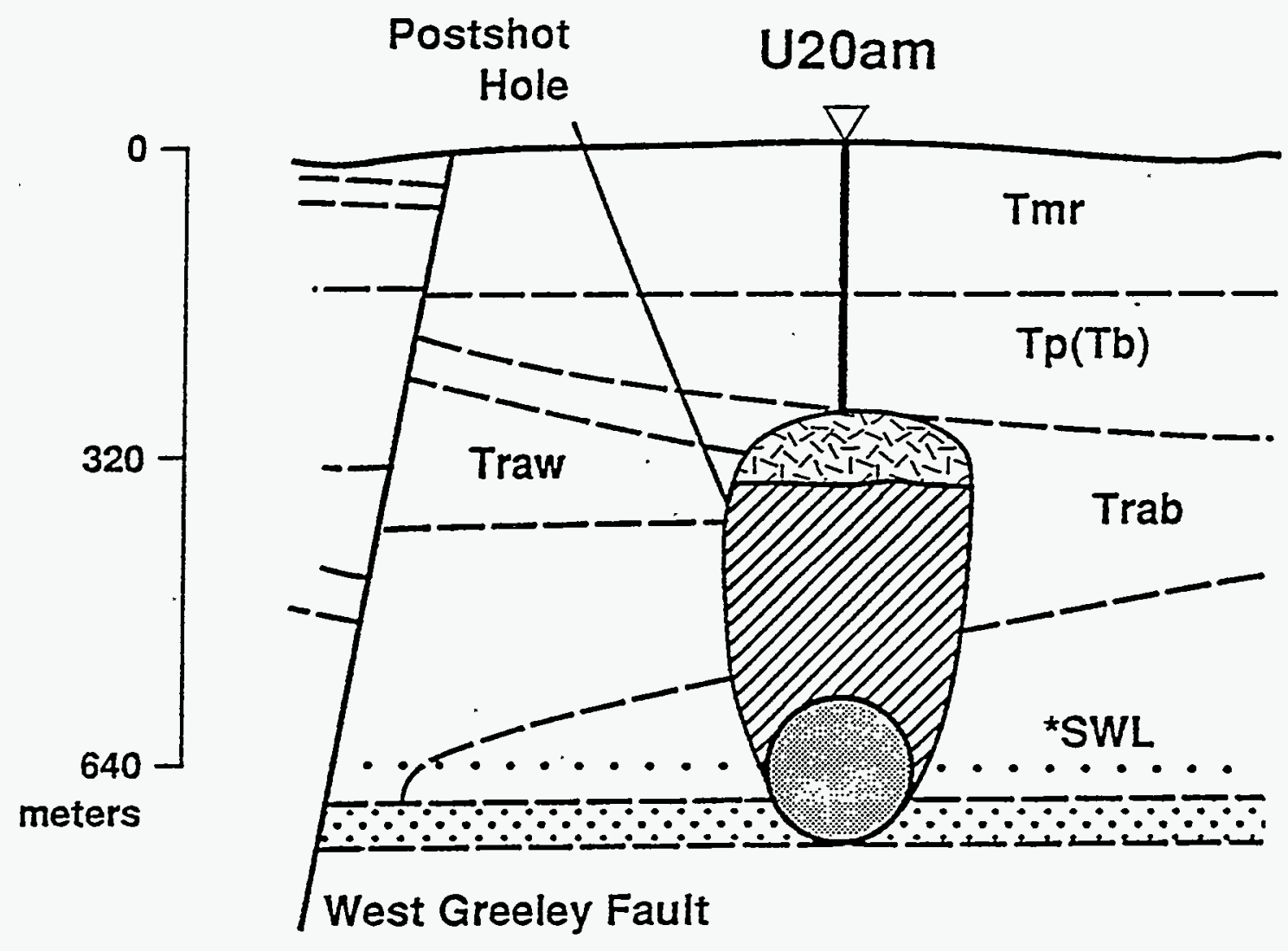

Figure 1. Schematic of a partially collapsed chimney having a loosely compacted crown beneath a relatively competent overburden extending from 320 meters to the surface. The sphere centered at 640 meters indicates the size and location of the explosively produced cavity prior to collapse. The slanting postshot drillhole is used for the measurement of subsurface pressure and the injection of tracer gases. 


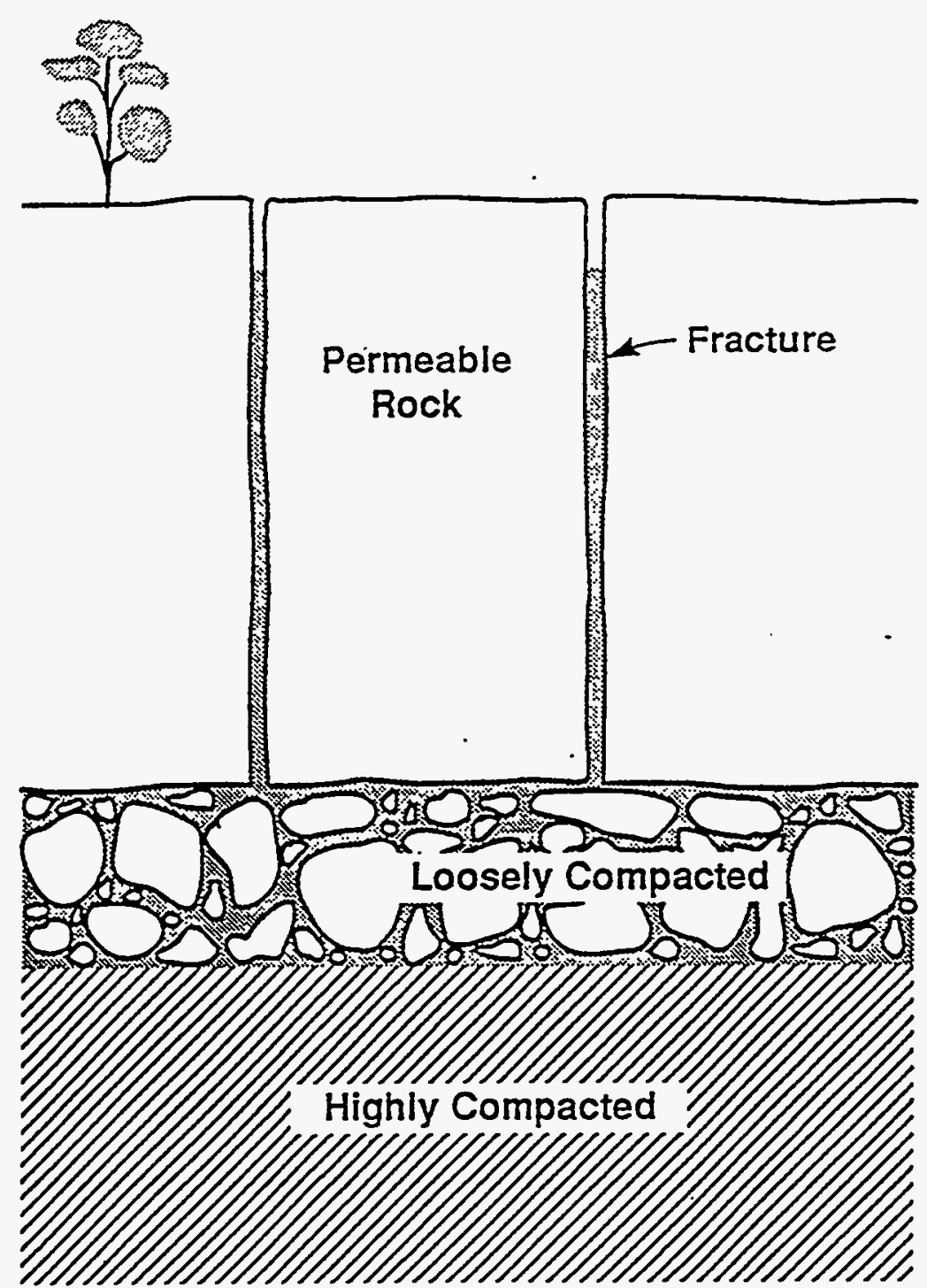

Figure 2. Conceptual model of the atmospheric pumping process, with a loosely compacted rubble region breathing through one or more vertical fractures. Successive cycles of barometric pumping carry contaminated gases incrementally higher, as molecular diffusion carries contaminants deeper into the air-filled porosity of the fracture walls. 


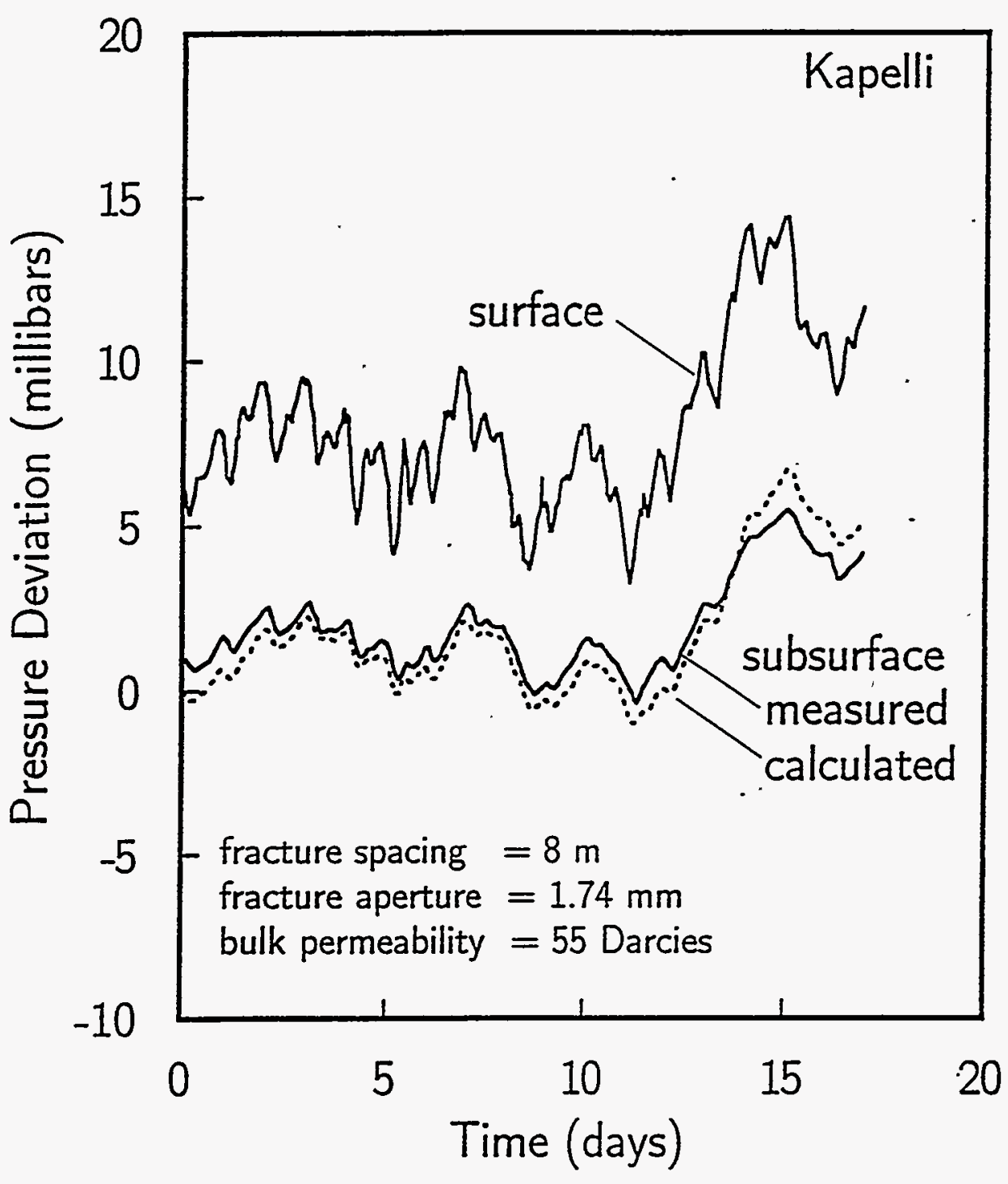

Figure 3. Kapelli is one of the heaviest breathers of all measured chimneys, as judged from the close correspondence between the subsurface chimney pressure and barometric pressure at the surface (solid lines). Since all pressure histories are presented as deviations from the static head, curves are shifted vertically for clarity. The effective bulk permeability of the overburden is inferred to be on the order of 50 to 100 Darcies based on numerical simulations like the one shown here (dotted line) for a fracture spacing and aperture of $8 \mathrm{~m}$ and $1.74 \mathrm{~mm}$, respectively. The comparative calculation uses the measured surface pressure as input data. 
[

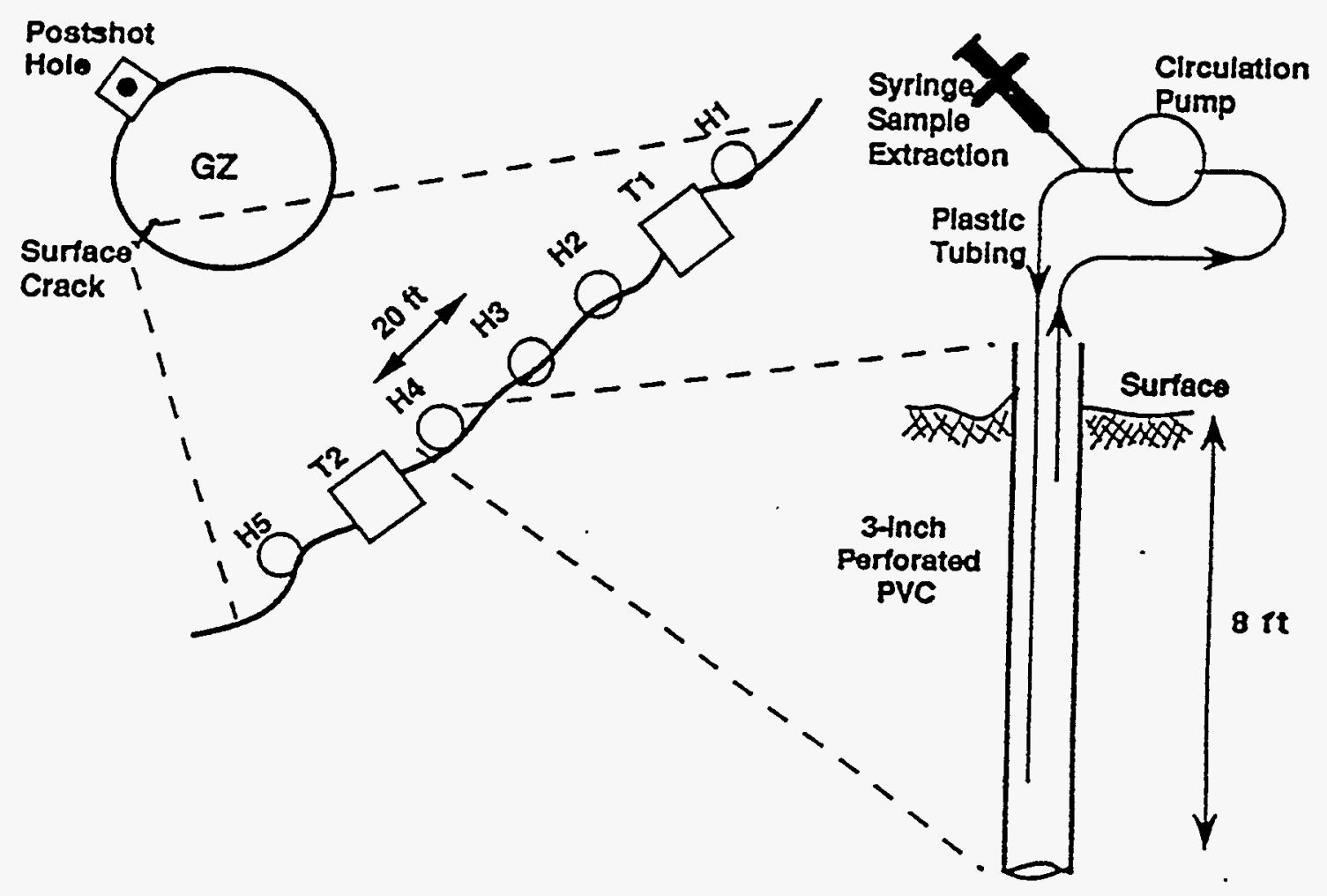

Figure 4. A prominent surface crack located near the perimeter exclusion fence was monitored with tarps and shallow collection holes intended to capture contaminated gases and tracer gases near the earth's surface. 


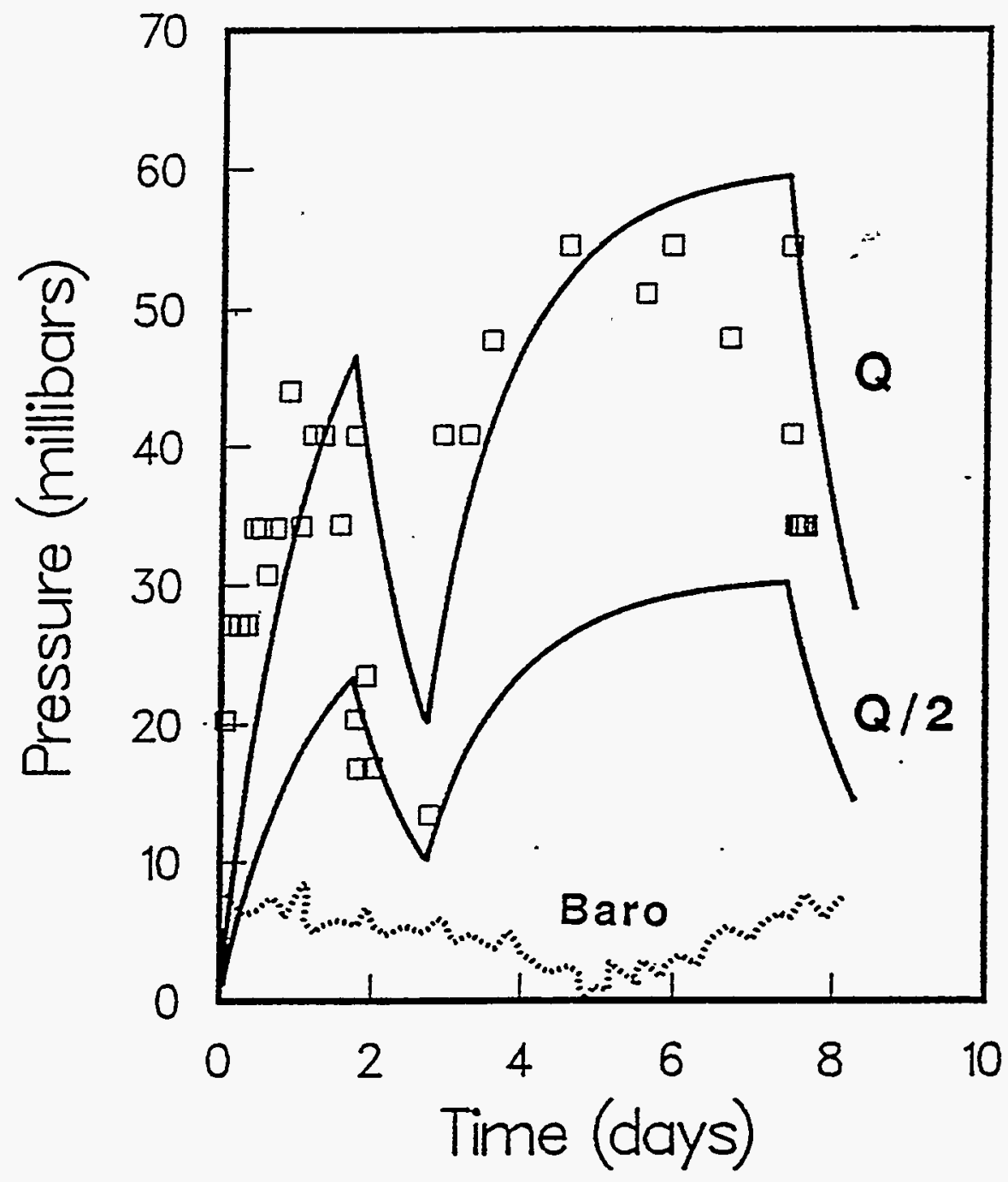

Figure 5. Chimney pressurization data (symbols) appear to be in reasonable agreement with theoretical calculations (solid lines) in which all or half of the measured air flow ( $Q=1500$ SCFM) is injected into a subsurface void containing one cavity volume beneath a 320 meter overburden having a permeability of 50 Darcies. The barometric pressure (dotted line) experienced a moderate 8-millibar cycle during the injection. 
狩

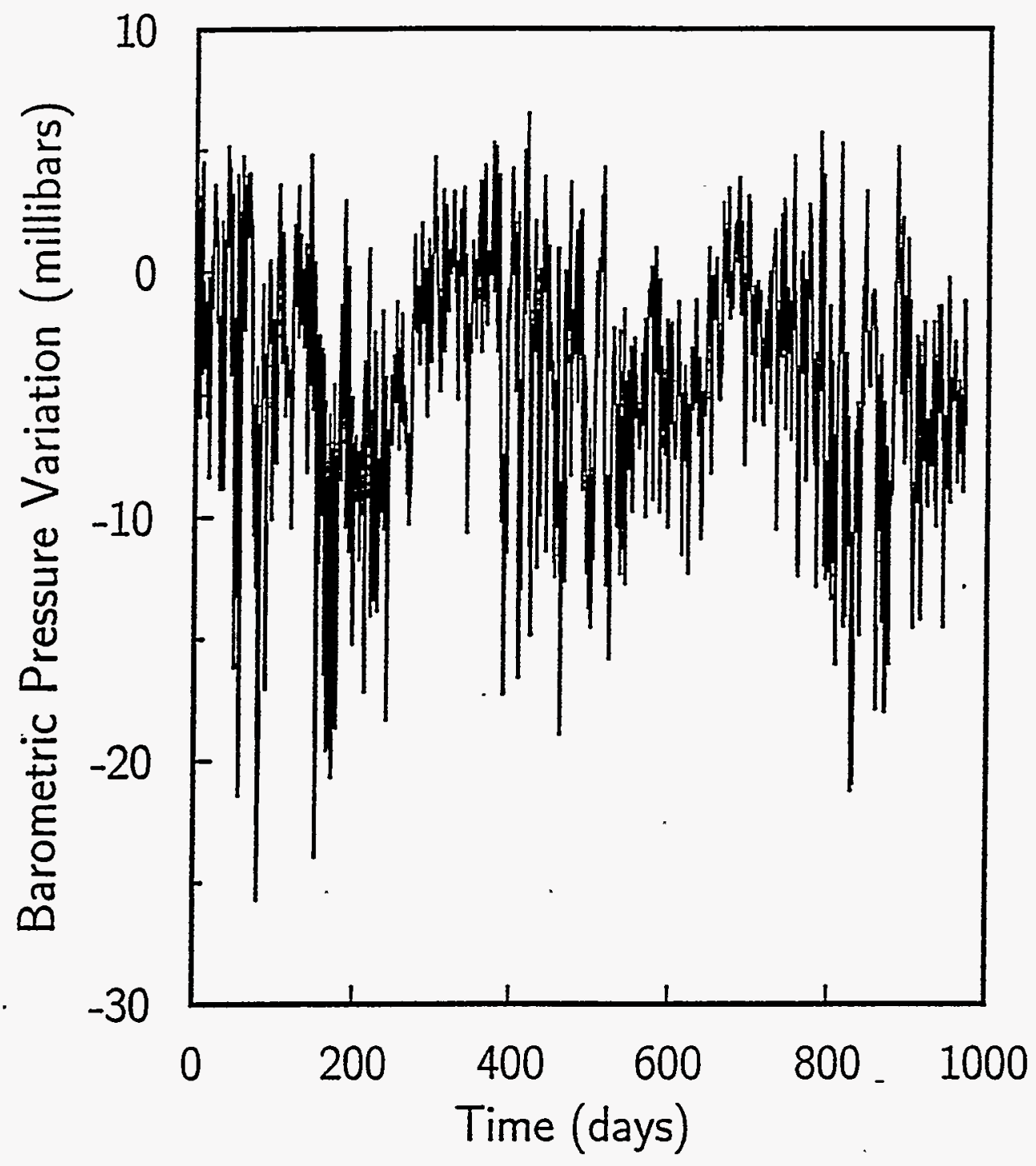

Figure 6. Barometric pressure history for the period following the injection of Kapelli which was completed on 10/2/92. Tierra injection was completed 322 days later on $8 / 23 / 93$. Barometric pressure data was supplied by the NOAA weather station situated in Area 20 of NTS. This pressure history was used as input data for all numerical simulations of the barometric pumping process. 


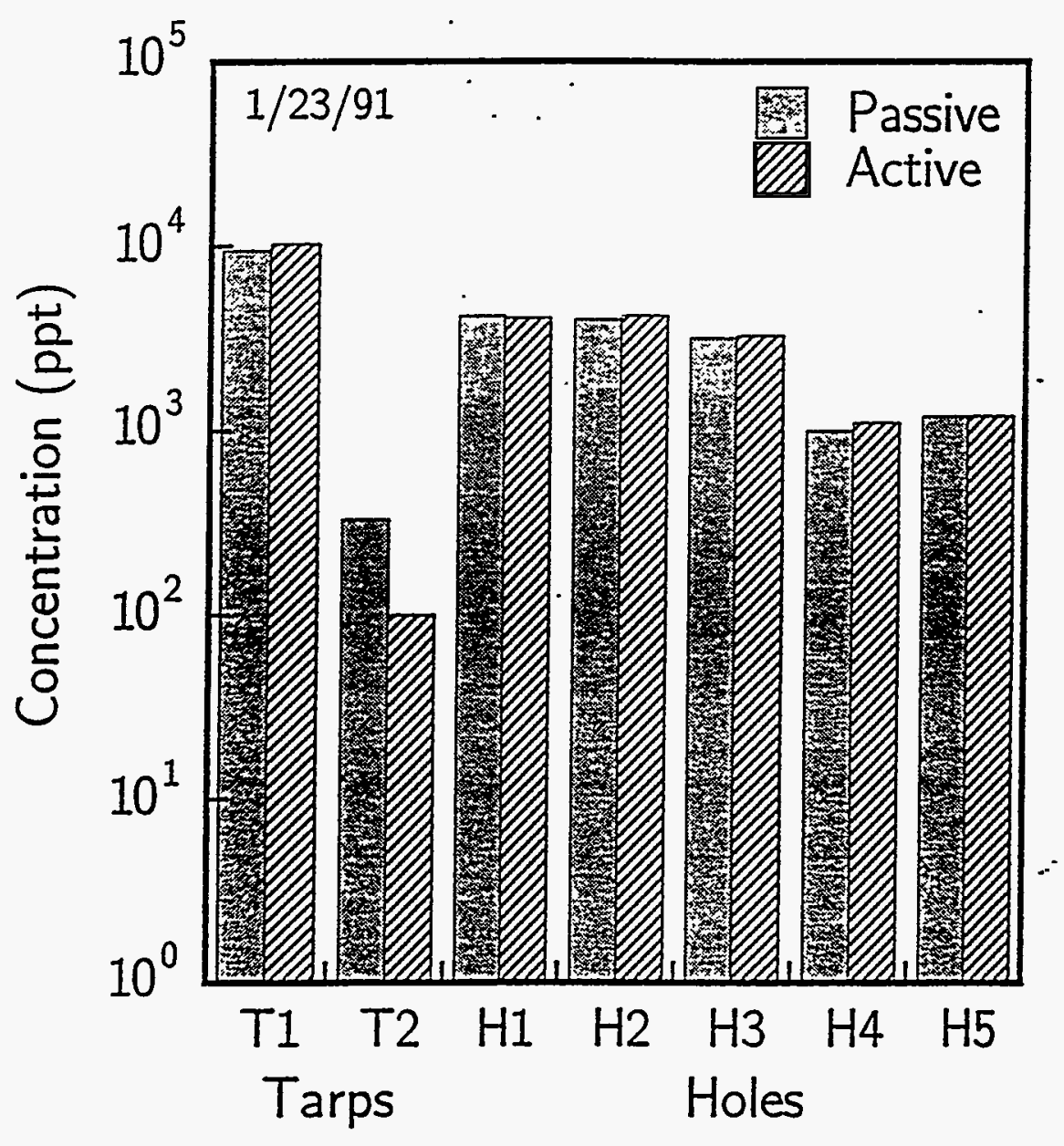

Figure 7. Nearly equal concentrations (parts per trillion) of active and passive tracers measured four months after injection (1/23/91 @13:00) suggest that tracer transport by barometric pumping was not greatly influenced by the active versus passive emplacement techniques. Spacial uniformity of samples is remarkable, considering the nature of the experiment and the medium.

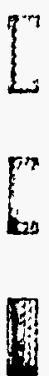




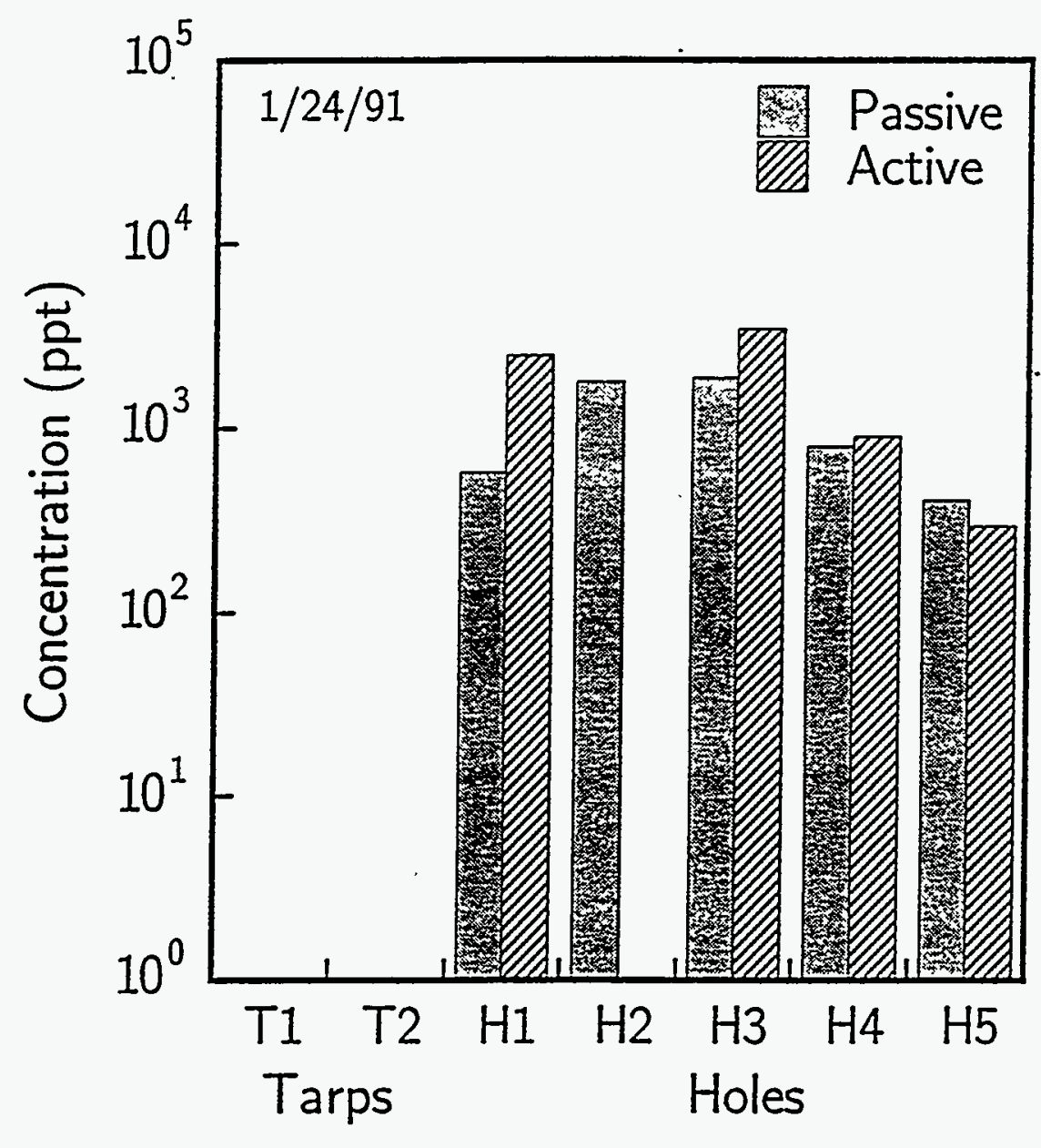

Figure 8. Tracer concentrations measured during a period of rising barometer (1/24/91@09:00) show that the collection holes have a longer retention of tracer than the tarps when fresh air is being inhaled into the earth's surface. 


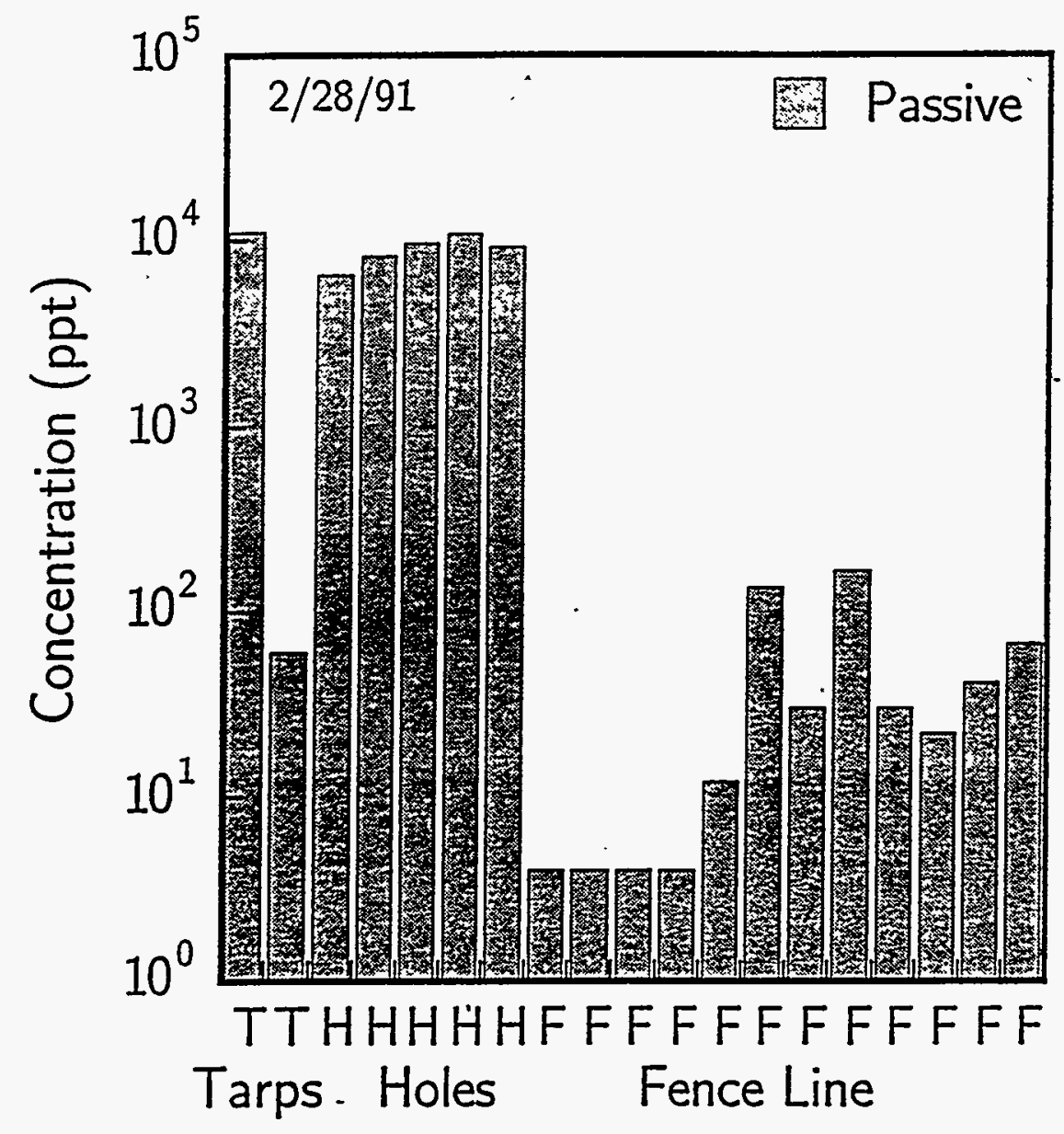

Figure 9. A series of soil gas samples collected at regular intervals along the exclusion fence (2/28/91@16:00) have tracer concentrations comparable to that in tarp\#2, suggesting that there may be a large number of cracks which participate in the breathing process. 


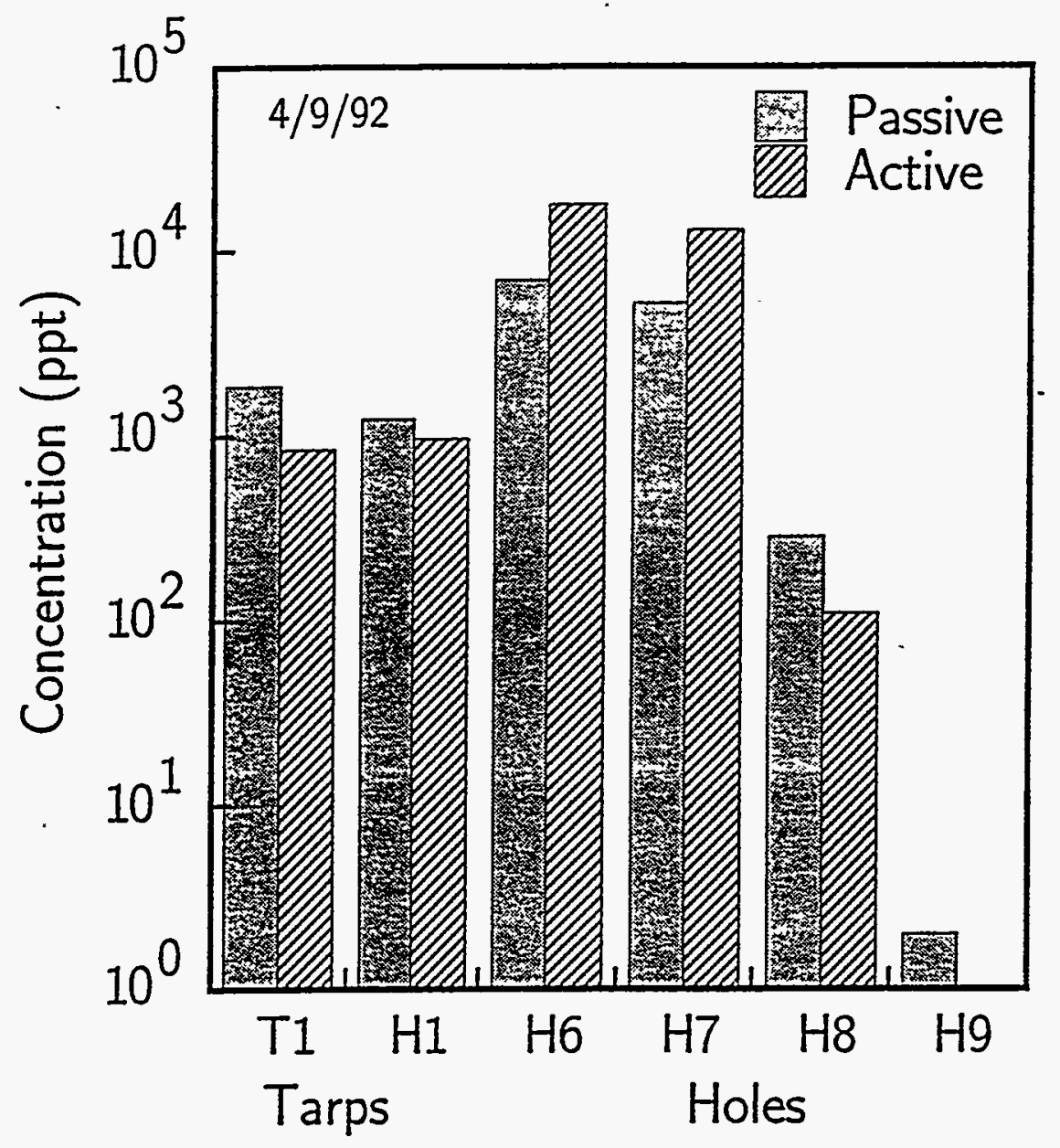

Figure 10. Samples from holes\#6 and \#7 have tracer concentrations consistently greater than those taken from tarp\#1 and hole\#1, indicating that this region is even better connected to the subsurface than the area initially targeted. Moreover, the concentration of the active tracer in holes \#6 and \#7 always exceeds that of the passive tracer, suggesting that the injection of air pushed the active tracer toward holes \#6 and \#7. 


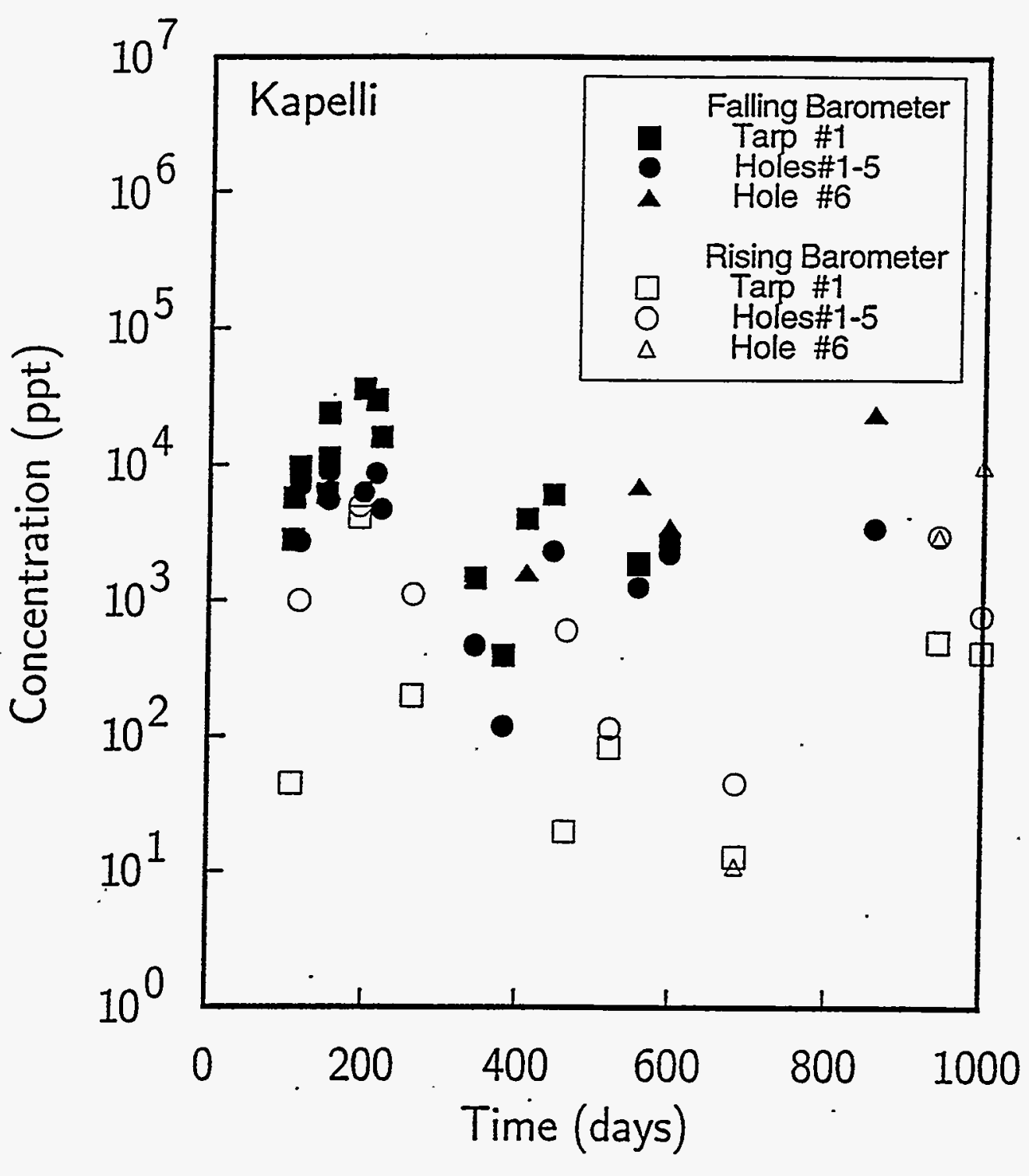

Figure 11. Time history of passive SF6 tracer concentration comparing tarp\#1 (squares) with the average of nearby holes \#1 through \#5 (circles) and with the more remote hole\#6 (triangles). Highest concentrations were recorded when the barometer was falling (solid symbols) and, at those times, tarp \#1 had a higher concentration than nearby holes. Incomplete mixing may explain early peak of measured concentrations.

? 


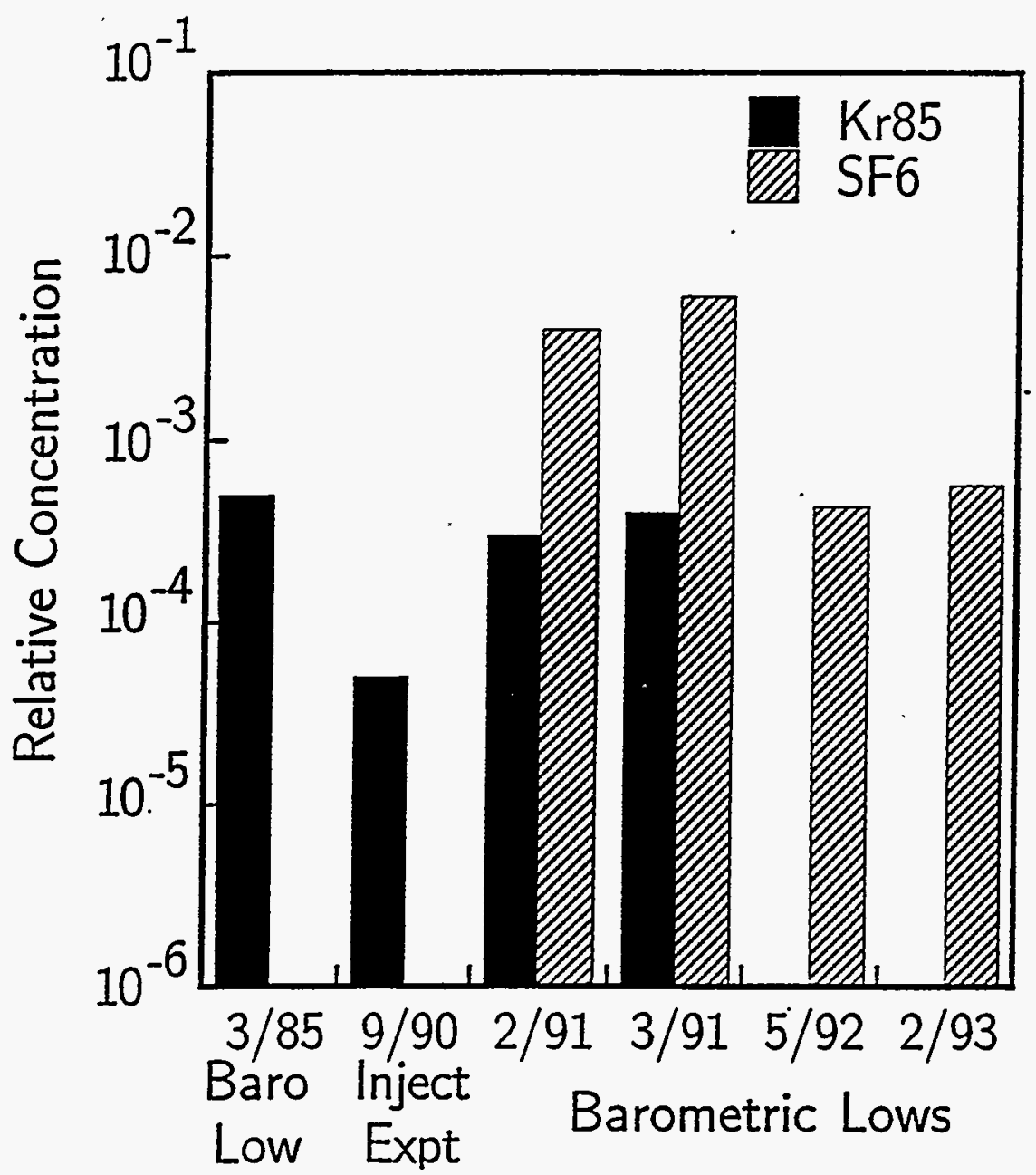

Figure 12. Radioactive Krypton produced by the 1984 explosion is still breathing out of the ground. Comparison of 1985 and 1991 samples suggests that the subsurface inventory of $\mathrm{Kr}$ is being depleted very slowly. Low $\mathrm{Kr}$ concentration during 1990 injection indicates that the vertical flow was weaker than that associated with barometric lows. High concentration of SF6 during 1991 may indicate that SF6 was not yet well mixed with chimney gas. SF6 concentrations measured in 1992 and 1993 are comparable to $\mathrm{Kr}$ measurements in 1985 and 1991. No $\mathrm{Kr}$ measurements were made after 1991. 


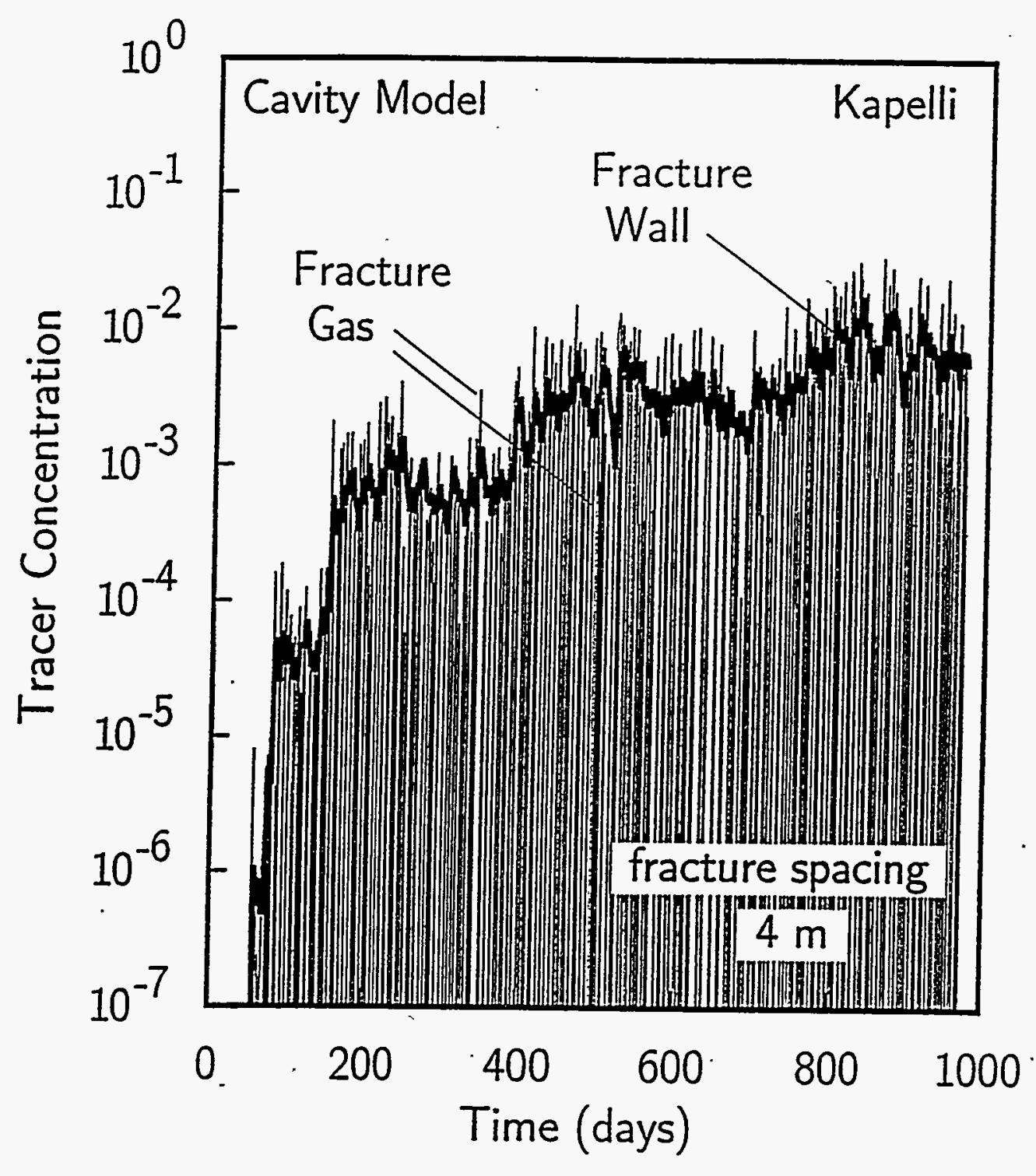

Figure 13. Numerical calculation of the near-surface tracer concentration in flowing gases within cracks (vertical spikes) and stagnant gases within the fracture wall (heavy solid line). The erratic concentration in cracks is analogous to samples extracted from tarps, whereas the calculated concentration within the fracture wall is damped by molecular diffusion, in analogy with collection holes. The primary "adjustable" parameter in the model is the unknown fracture spacing which is taken as 4 meters in this simulation. 
遂

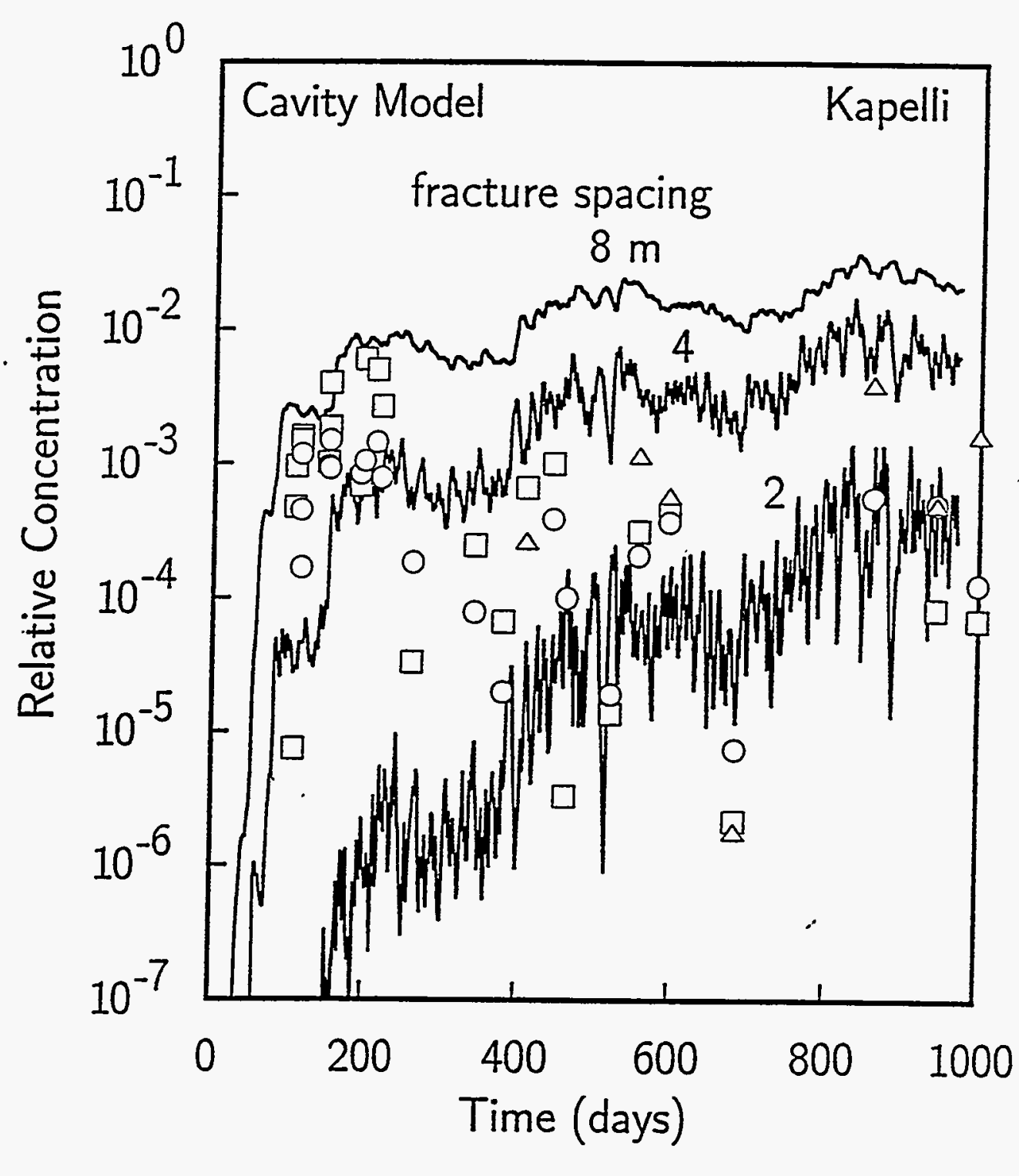

Figure 14. Measurements of passive SF6 concentration in tarp\#I (squares) and holes (circles and triangles) are consistent with numerical calculations (solid lines) for a fracture spacing of 2-4 meters. Data shown here is the same as in Figure 10 except that it is now normalized by the estimated subsurface concentration. Calculations suggest that the effluent concentration increases with fracture spacing. 


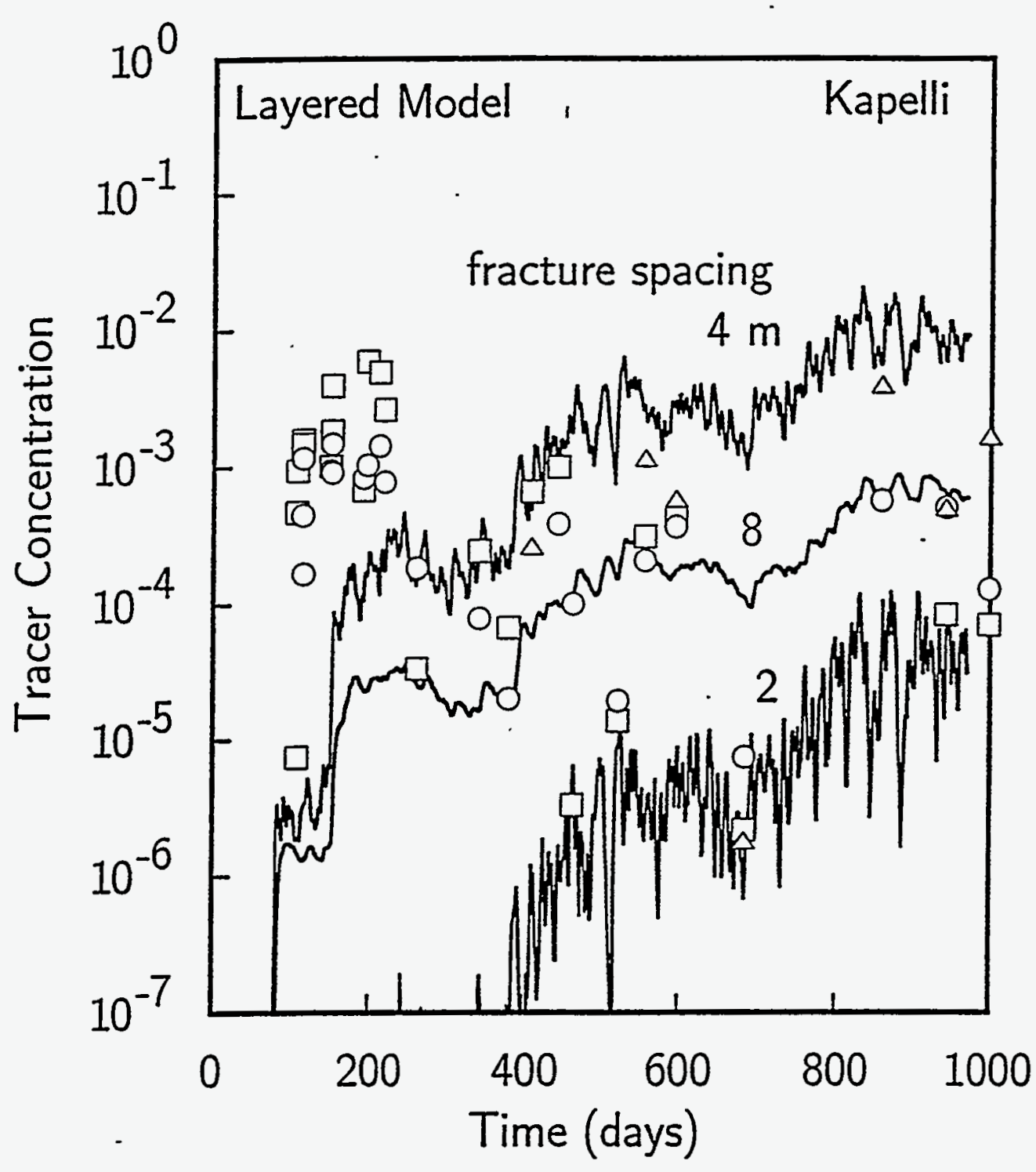

Figure 15. Comparison of measured SF6 data (symbols) with calculations (solid lines) for a "layered" model in which the fractured overburden is the same in the previous Figure 14 but the region beneath is now assumed to be a rubble pile having most of its air-filled porosity contained within the permeable rubble blocks, as opposed to the earlier "cavity" model which assumed that the air filled porosity of the lower region was so well connected that the pressure and tracer concentration were uniform throughout.

[ 


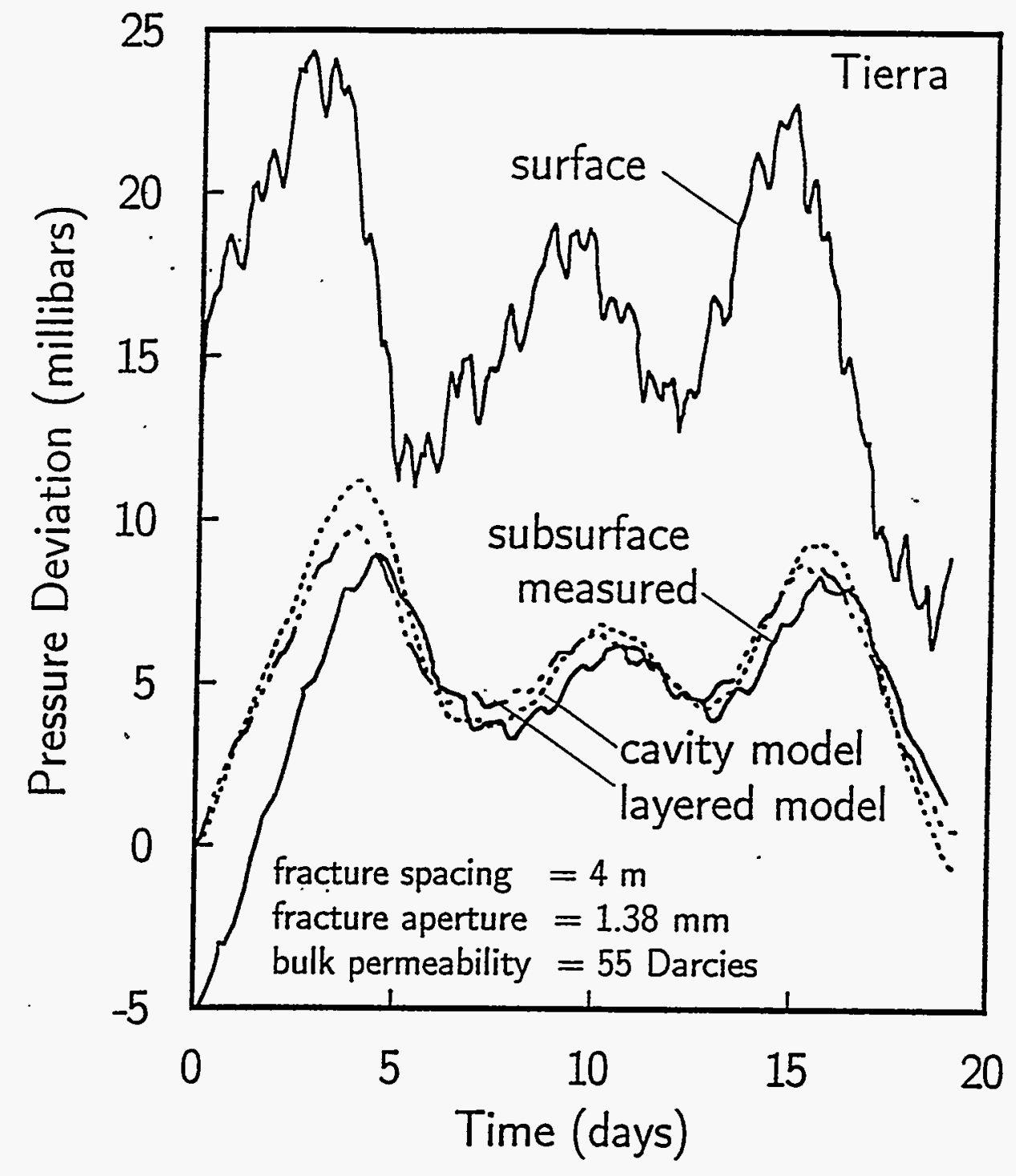

Figure 16. Subsurface pressure at Tierra follows barometric pressure with about 50\% attenuation, in close correspondence with data shown earlier for Kapelli. As before, measured subsurface pressure is reasonably well predicted by calculations in which the bulk permeability of the fractured overburden is on the order of 50-100 Darcies. Pressure response of alternative "cavity" and "layered" models is quite comparable when both have the same overburden properties and subsurface air volume. 


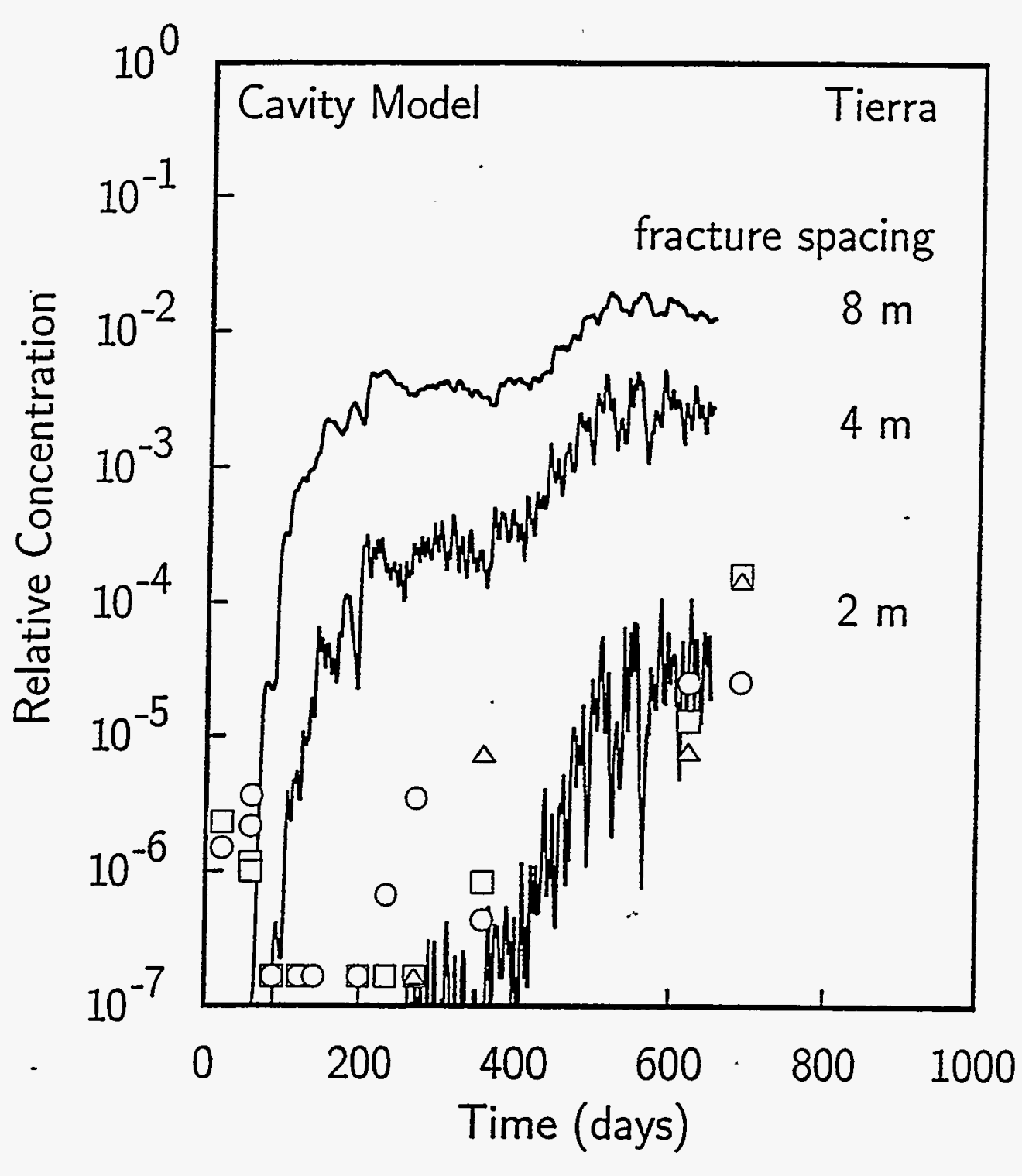

Figure 17. Comparison of numerical simulations of Tierra experimant (solid lines) with measured SF6 concentration in tarp\#1 (squares), average of holes \#1-3 (circles), and remote hole \#6 (triangles). The calculations suggest that the relatively slow arrival of tracer at Tierra may be caused by a fracture spacing $(\sim 2 \mathrm{~m})$ which is roughly half as great as that inferred at Kapelli ( $4 \mathrm{~m})$. Also, the barometric cycles were more severe in the winter after Kapelli, as can be seen by comparing the calculational results for the two cases. 


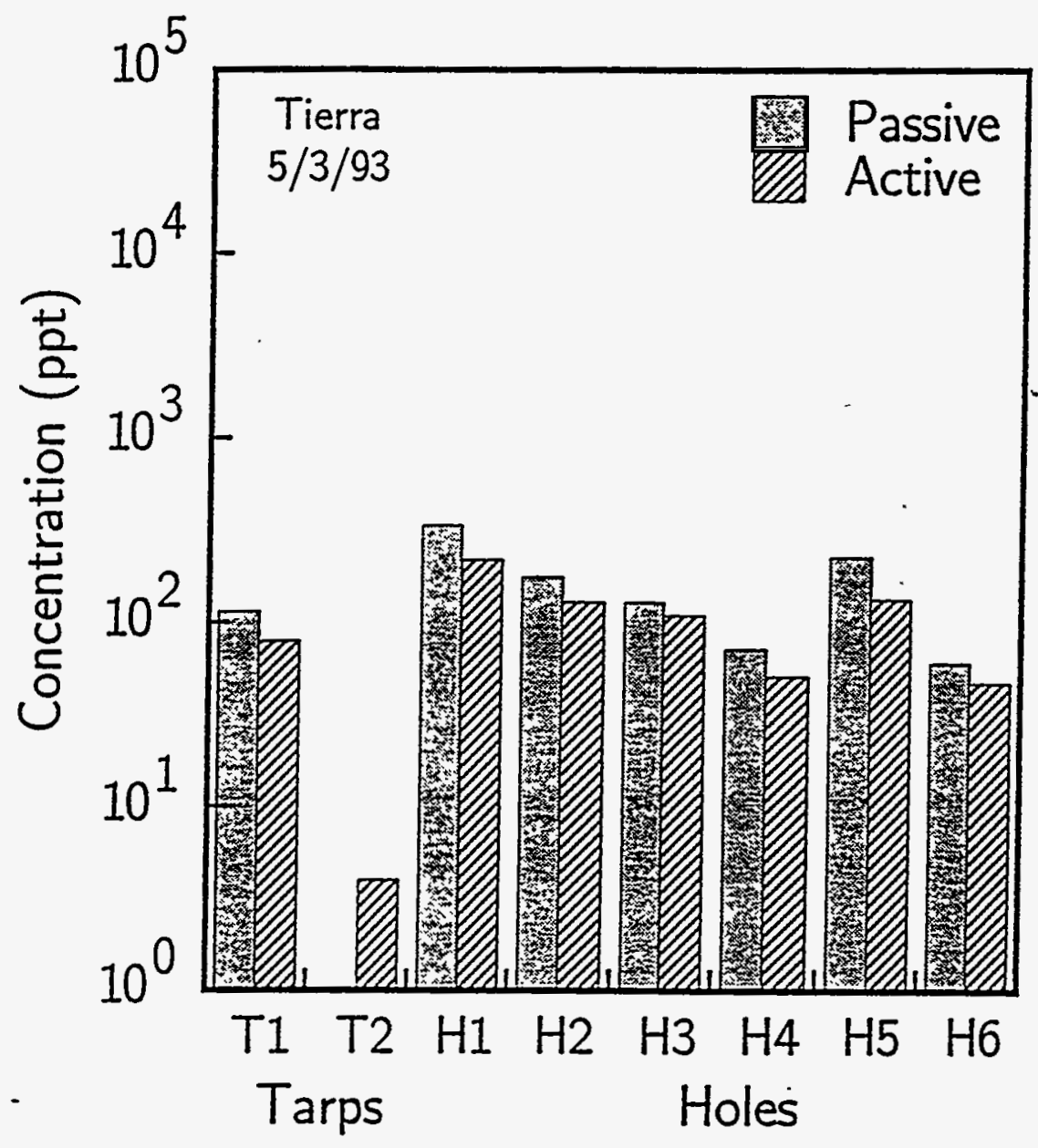

Figure 18. Toward the end of the monitoring period, active and passive tracer concentrations were quite comparable at Tierra. There was also a remarkable uniformity among widely spread holes and tarps. Both of these observations were also typical of Kapelli, although the concentrations were generally greater at Kapelli.

I.

E? 


\begin{tabular}{|c|c|c|c|c|c|c|c|c|c|}
\hline \multicolumn{3}{|c|}{ Time } & \multicolumn{7}{|c|}{ SF6 Concentration (ppt) } \\
\hline $\mathrm{m} / \mathrm{d} / \mathrm{y}$ & hour & day & $\mathrm{T} 1$ & $\mathrm{~T} 2$ & $\mathrm{H1}$ & $\mathrm{H} 2$ & $\mathrm{H3}$ & $\mathrm{H} 4$ & $\mathrm{H} 5$ \\
\hline $01 / 15 / 91$ & $16: 00$ & 106 & 2800 & 3 & & & & & \\
\hline $01 / 16$ & $10: 00$ & 107 & 45 & 4 & & & & & \\
\hline $01 / 16$ & $14: 00$ & 107 & 5700 & 11 & & & & & \\
\hline $01 / 23$ & $13: 00$ & 114 & 9600 & 332 & 4200 & 4000 & 3200 & 1000 & 1200 \\
\hline $01 / 23$ & $15: 00$ & 114 & 8900 & 282 & 4400 & 10900 & 9300 & 9400 & 1100 \\
\hline $01 / 24$ & 09:00 & 115 & 0 & 0 & 582 & 1800 & 1900 & 1800 & 410 \\
\hline $02 / 27$ & $13: 40$ & 149 & 6100 & 304 & 12600 & 5200 & .7200 & 1500 & 1900 \\
\hline $02 / 28$ & $14: 30$ & 150 & 24000 & 353 & 7400 & 6400 & 6500 & 3000 & 4300 \\
\hline $02 / 28$ & $16: 00$ & 150 & 11200 & 60 & 6600 & 8300 & 9700 & 11000 & 9200 \\
\hline $04 / 10$ & $14: 00$ & 191 & 4100 & 25 & 7100 & & 6400 & & 1500 \\
\hline $04 / 15$ & $12: 30$ & 196 & 35900 & 600 & & 4000 & 10000 & 4500 & 6500 \\
\hline $05 / 01$ & $14: 30$ & 212 & 30000 & & 11800 & 12600 & 9200 & 4300 & 5500 \\
\hline $05 / 08$ & $14: 38$ & 219 & 16800 & 140 & 5000 & 7000 & 5700 & 3000 & 2800 \\
\hline \multirow[t]{2}{*}{$06 / 20$} & $10: 00$ & 262 & 200 & 0 & 1550 & 1005 & 630 & 1850 & 490 \\
\hline & & & $\mathrm{T} 1$ & & $\mathrm{HI}$ & $\mathrm{H} 6$ & $\mathrm{H} 7$ & H8 & $\mathrm{H9}$ \\
\hline 09/09 & $10: 45$ & 343 & 1460 & & 475 & & & & \\
\hline $10 / 15$ & $16: 37$ & 379 & 255 & & 77 & & & & \\
\hline $10 / 16$ & $16: 18$ & 380 & 400 & & 120 & & & & \\
\hline $11 / 14$ & $15: 05$ & 409 & 4000 & & & 1600 & & & \\
\hline $12 / 18$ & $15: 16$ & 443 & 6050 & & 2300 & & & & * \\
\hline $01 / 06 / 92$ & $13: 44$ & 462 & 20 & & 605 & & & & \\
\hline 03/05 & $14: 10$ & 521 & 83 & & 116 & & & & \\
\hline 04/09 & $14: 56$ & 556 & 1870 & & 1250 & 7000 & 5300 & 285 & 2 \\
\hline $05 / 19$ & $14: 46$ & 596 & 2600 & & 2200 & 3500 & & & \\
\hline $08 / 14$ & $14: 31$ & 683 & 13 & & 45 & 11 & & & \\
\hline $02 / 08 / 93$ & $13: 56$ & 860 & & & 3400 & 24000 & & & \\
\hline $05 / 03$ & $14: 41$ & 944 & 500 & & 3000 & & & & \\
\hline $07 / 07$ & & 1010 & 420 & & 770 & 10000 & & & \\
\hline
\end{tabular}

Table 1. SF6 concentrations measured at Kapelli. This is the passive tracer that was introduced at the end of the air injection period. The "Day" column indicates ellapsed time after completing tracer injection on 10/1/90. From day 106 through 262, tarps \#1 and \#2 (T1 and T2) were regularly sampled along with holes \#1 through \#5 (H1 through H5). From day 343 through 1010, tarp\#1 and hole\#1 were sampled along with holes \#6 through \#9 which were drilled in August of 1991. 


\begin{tabular}{|c|c|c|c|c|c|c|c|c|c|}
\hline \multicolumn{3}{|c|}{ Time } & \multicolumn{7}{|c|}{ 13B1 Concentration (ppt) } \\
\hline $\mathrm{m} / \mathrm{d} / \mathrm{y}$ & hour & day & $\mathrm{T} 1$ & $\mathrm{~T} 2$ & $\mathrm{H} 1$ & $\mathrm{H} 2$ & $\mathrm{H}^{2}$ & $\mathrm{H} 4$ & H5 \\
\hline $01 / 15 / 91$ & $16: 00$ & 106 & 900 & 0 & & & & & \\
\hline $01 / 16$ & $10: 00$ & 107 & 0 & 0 & & & & & \\
\hline $01 / 16$ & $14: 00$ & 107 & 6000 & 0 & & & & & \\
\hline $01 / 23$ & $13: 00$ & 114 & 10400 & 100 & 4100 & 4200 & 3300 & 1100 & 1200 \\
\hline $01 / 23$ & $15: 00$ & 114 & 9100 & 0 & 4100 & 4300 & 3300 & 1200 & 900 \\
\hline $01 / 24$ & 09:00 & 115 & 0 & 0 & 2500 & & 3500 & 900 & 300 \\
\hline $02 / 27$ & $13: 40$ & 149 & 7300 & 0 & 3900 & 3800 & 2600 & 1300 & 0 \\
\hline $02 / 28$ & $14: 30$ & 150 & 15000 & 200 & 2100 & 5600 & 4500 & 2400 & 2600 \\
\hline $02 / 28$ & $16: 00$ & 150 & 6700 & 0 & 4300 & 2400 & 2400 & 1800 & 2000 \\
\hline 04/10 & $14: 00$ & 191 & 3000 & 0 & 5200 & & 4900 & & 2100 \\
\hline $04 / 15$ & $12: 30$ & 196 & 21600 & 0 & & 3100 & 7600 & & \\
\hline 05/01 & $14: 30$ & 212 & & & & & & & \\
\hline 05/08 & $14: 38$ & 219 & & & & & & & \\
\hline \multirow[t]{2}{*}{$06 / 20$} & $10: 00$ & 262 & 81 & 0 & 650 & 445 & 300 & 625 & 202 \\
\hline & & & $\mathrm{T} 1$ & & $\mathrm{H} 1$ & H6 & $\mathrm{H} 7$ & $\mathrm{H} 8$ & $\mathrm{H} 9$ \\
\hline 09/09 & $10: 45$ & 343 & 817 & & 408 & & & & \\
\hline $10 / 15$ & $16: 37$ & 379 & 180 & & 195 & & & & \\
\hline $10 / 16$ & $16: 18$ & 380 & 280 & & 220 & & & & \\
\hline $11 / 14$ & $15: 05$ & 409 & 700 & & & 14000 & & & \\
\hline $12 / 18$ & $15: 16$ & 443 & 1930 & & 2070 & & & & \\
\hline $01 / 06 / 92$ & $13: 44$ & 462 & 200 & & 415 & & & & \\
\hline $03 / 05$ & $14: 10$ & 521 & 70 & & 85 & & & & \\
\hline 04/09 & $14: 56$ & 556 & 850 & & 970 & 18000 & 13000 & 110 & \\
\hline 05/19 & $14: 46$ & 596 & 2500 & & 1350 & 1150 & & & \\
\hline $08 / 14$ & $14: 31$ & 683 & 50 & & $<30$ & $<30$ & & & \\
\hline $02 / 08 / 93$ & $13: 56$ & 860 & & & 5700 & 57000 & & - & \\
\hline $05 / 03$ & $14: 41$ & 944 & 510 & & 7000 & & & & \\
\hline $07 / 07$ & & 1010 & 200 & & $<140$ & 24000 & & & \\
\hline
\end{tabular}

Table 2. $13 \mathrm{~B} 1$ concentrations measured at Kapelli. This is the active tracer that was introduced at the beginning of the air injection period. In all other respects this table is comparable to Table 1. 


\begin{tabular}{lcc|rrrrrrrr}
\hline & \multicolumn{1}{c|}{ Time } & \multicolumn{8}{c}{ SF6 Concentration (ppt) } \\
$\mathrm{m} / \mathrm{d} / \mathrm{y}$ & hour & day & T1 & $\mathrm{T} 2$ & H1 & H2 & H3 & H4 & H5 & H6 \\
\hline $09 / 09$ & $10: 05$ & 21 & 14 & & 23 & 2 & 2 & & & \\
$10 / 15$ & $15: 53$ & 57 & 7 & & 10 & 16 & 14 & & & \\
$10 / 16$ & $15: 35$ & 58 & 6 & & 28 & 22 & 16 & & & \\
$11 / 14$ & $14: 14$ & 87 & BG & BG & 10 & 8 & 8 & & 6 & \\
$12 / 18$ & $14: 42$ & 121 & BG & & BG & BG & BG & & BG & \\
$01 / 06 / 92$ & $13: 08$ & 140 & & & BG & BG & BG & & & \\
$03 / 05$ & $13: 20$ & 199 & BG & BG & BG & BG & BG & & BG & \\
$04 / 09$ & $14: 08$ & 234 & BG & BG & 5 & 5 & 2 & BG & BG & \\
& & & & & & & & & & \\
$05 / 19$ & $15: 17$ & 274 & BG & BG & 31 & 19 & 14 & & & BG \\
$08 / 14$ & $15: 30$ & 361 & 5 & 2 & 4 & 2 & 2 & & & 45 \\
$02 / 08 / 93$ & & 538 & & & & & & & & \\
$05 / 03$ & $14: 09$ & 622 & 80 & 4 & 220 & 130 & 110 & 51 & 134 & 47 \\
$07 / 07$ & & 688 & 960 & 16 & 280 & 54 & 130 & 380 & 41 & 870 \\
\hline
\end{tabular}

\begin{tabular}{lcc|rrrrrrrr}
\hline & Time & \multicolumn{8}{|c}{ 13B1 Concentration (ppt) } \\
$\mathrm{m} / \mathrm{d} / \mathrm{y}$ & hour & day & \multicolumn{1}{c|}{$\mathrm{T} 1$} & $\mathrm{~T} 2$ & $\mathrm{H} 1$ & $\mathrm{H} 2$ & $\mathrm{H} 3$ & $\mathrm{H} 4$ & $\mathrm{H} 5$ & $\mathrm{H} 6$ \\
\hline $05 / 19$ & $15: 17$ & 274 & 0 & 0 & 140 & 75 & 40 & & \\
$08 / 14$ & $15: 30$ & 361 & $<30$ & $<30$ & $<30$ & $<30$ & $<30$ & & & $<30$ \\
$02 / 08 / 93$ & & 538 & & & & & & & & \\
$05 / 03$ & $14: 09$ & 622 & 115 & 0 & 340 & 180 & 130 & 72 & 230 & 60 \\
$07 / 07$ & & 688 & $<140$ & $<140$ & $<140$ & $<140$ & 280 & $<140$ & $<140$ & $<140$ \\
\hline
\end{tabular}

Table 3. SF6 (active) and 13B1 (passive) concentrations measured at Tierra. Day column indicates time elapsed after completing injection of Tierra on $8 / 23 / 91$. Since this is 322 days after injection of Kapelli, the day entries in this table differ by 322 from those given in previous Kapelli tables, even though samples were always collected from both sites on the same calendar days. The lower table does not show data for samples extracted from Tierra on 9/9/91 through 4/9/92, since no $13 B 1$ was detected. 